\title{
Prerequisites for Laparoscopic Hysterectomies
}

\author{
${ }^{1}$ Liselotte Mettler, ${ }^{2}$ Ibrahim Alkatout
}

\section{ABSTRACT}

Let us start with the question, if instruments make good surgeon? Instruments and apparatuses for laparoscopic hysterectomies have been developed over the last 40 years for interventions with multiple ports as well as for single-port surgery. A good surgeon bases his surgical plan on his knowledge of anatomy, recognizing the presented disease, his intuitiveness, and on optimal instruments and coagulation systems.

With this issue, we are dealing in three parts:

1. History

2. General systems for adhesion prevention, mesh, stitching and knotting techniques, staples, glue, drains, rinsing solutions, and suction

3. Instruments and apparatuses for laparoscopic hysterectomies Instrument trolleys gather all equipment used in gynecological and general laparoscopic surgery. These smart carts are available as rolling carts or on special platforms hanging down from the ceiling. Operating room settings, like OR $1^{\mathrm{TM}} \mathrm{Neo}$ (Karl Storz GmbH, Tuttlingen, Germany) or the Endoalpha or Visera Elite of Olympus or the Stryker unit with SDC Ultra as digital documentation system, form the basis to position the necessary equipment for easy use of the surgeon.

The idea of warming and humidifying the $\mathrm{CO}_{2}$ gas to avoid peritoneal damage has been well described by Philippe Konincks and Douglas Ott. The HumiGard ${ }^{\mathrm{TM}}$ of Fisher and Paykel Health care (Auckland, New Zealand) provides heated, filtered, and humidified gas for abdominal insufflation with a predetermined temperature.

Today, every $\mathrm{CO}_{2}$ pneu automatic provides up to $37^{\circ} \mathrm{C}$ heated $\mathrm{CO}_{2}$ gas, which is controlled by a pressure regulator within the machine by applying the Quatro-test. In the Quatrotest, the volume of gas flowing through the Veress needle during insufflation, intra-abdominal pressure, total volume, and preset filling pressure are measured. Cold light provided by xenon lamps is already substituted by light-emitting diode light. Video camera setup with three-chip cameras is substituted recently by $\mathrm{HC}$ camera systems and can be used for laparoscopy as well as in hysteroscopy. High-resolution video with video monitors guarantees optimal picture quality. The technological development allows the use of larger monitors in high-definition quality that facilitates a relaxed working atmosphere for the surgeon.

A realistic, nearly true to life three-dimensional (3D) picture is possible due to various technological elements, such as digital simulation, a second camera system, or the use of shutter lens. Digital devices for the video camera control the picture

\footnotetext{
${ }^{1}$ Professor Emeritus, ${ }^{2}$ Priv. Doz.

1,2Department of Obstetrics and Gynecology, University Clinics
} of Schleswig-Holstein, Kiel, Germany

Corresponding Author: Liselotte Mettler, Professor Emeritus Department of Obstetrics and Gynecology, University Clinics of Schleswig-Holstein, Kiel, Germany, e-mail: profmettler@gmx.de quality and facilitate automatic white balancing. The Karl Storz Company already offers the TRICAM 3D imaging system that allows the surgeon to view crisp, clear image through a pair of lightweight polarizing glasses. The ENDOCAMELEON laparoscope provides a viewing angle that can be adjusted continuously between 0 and 120 .

Keywords: Laparoscopic hysterectomies, Technical features.

How to cite this article: Mettler L, Alkatout I. Prerequisites for Laparoscopic Hysterectomies. Int J Gynecol Endsc 2018;2(1):6-21.

Source of support: Nil

Conflict of interest: None

\section{LAPAROSCOPIC HYSTERECTOMIES REQUIRE CERTAIN INSTRUMENTS}

\section{History}

Although the origin of endoscopy can be found already in a reference of the Babylonian Talmud, endoscopic surgery has been mainly developed by the use of Bozzini's light guide and the rigid optic system developed by Max Nize as cystoscope. We consider Georg Kelling (1866-1945) of Dresden who added his experience in oral air insufflation as the father of endoscopic surgery. The gastric recognition of pathologies and esophageal endoscopy is actually based on future research with diagnostic and therapeutic examination of enclosed body cavities.

In the field of gynecology, subtotal hysterectomy by laparotomy, total hysterectomy by laparotomy, and the vaginal uterine resection dominated till 1980 for the gynecologic surgical procedure. With the continuing development, the possibility of laparoscopic uterine resection was recognized by many gynecological surgeons. In Kiel, we applied laparoscopic assistance to vaginal hysterectomy, first published by Semm, ${ }^{1}$ and routinely in difficult vaginal hysterectomies. As in these early 1980s in Germany there existed still a great resistance for smaller laparoscopic interventions like myomectomies and ovarian cystectomies to be recognized by the responsible Medical Societies, we did not dare to even speak about laparoscopic hysterectomies. Even in our own Department of Obstetrics and Gynecology, where the uterus freed from the pelvic side wall by laparoscopy, in many occasions the uterus was then retracted through the vagina and the procedure was called laparoscopic assistance to vaginal hysterectomy. In our own department, colleagues blamed Kurt Semm and us as 
crazy handicapped surgeons, who need laparoscopy for a simple vaginal hysterectomy. We did not dissect the uterine vessels laparoscopically in those early years. Therefore, the worldwide acceptance of a published case on laparoscopic hysterectomy came from Reich et al. ${ }^{2}$ They published laparoscopic hysterectomy performed in the William Nesbitt Memorial Hospital in Kingston, Pennsylvania, USA. Simultaneously, $\mathrm{Semm}^{3}$ developed the subtotal laparoscopic hysterectomy (SLH) and performed on September 7, 1989 on a Saturday afternoon in Kiel and called it then "Classic Intrafascial Subtotal Hysterectomy," which was first published in 1993. In the same year, Jacques Donnez and Thomas Lyons published their approaches of SLH as well. Over the consecutive years till today, various modifications and classifications of laparoscopic hysterectomies for benign indications have been described. Laparoscopic radical hysterectomies date back to Dargent et al ${ }^{4}$ and have only been performed all over the world on a larger scale in the 21st century.

\section{GENERAL SYSTEMS FOR ADHESION PREVENTION, MESH, SUTURES, STAPLES, GLUE, DRAINS, RINSING SOLUTIONS, AND SUCTION}

\section{Adhesion Prevention with Liquids}

Adhesions during surgery are primarily defined as a condition in which bodily tissues that are normally separate grow together.

A fibrous band of scar tissue that binds together normally separates anatomical structures (Fig. 1). In this study, we want to stress the impact of adhesions, as defined above, as the most common postsurgical complication.

Adhesion formation is influenced by various factors. It starts with a trauma to the peritoneum or any other body site when rapid fibrin deposition occurs. In peritoneal

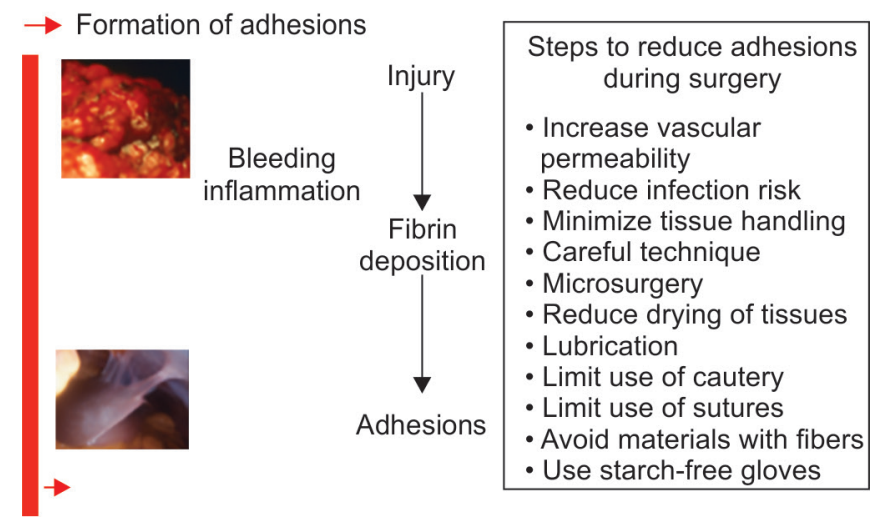

Fig. 1: Formation of adhesions healing, e.g., there is a balance between fibrin deposition and fibrinolysis. Any impairment of this process leads to increased fibrin deposition, the formation of fibrin strands, and stable adhesions may be formed. The incidence of intraperitoneal adhesions in patients following general abdominal or gynecological surgery ranges from 63 to $97 \%$.5,6 The overall risk of hospital readmission related to adhesions following either laparoscopic or open surgery is similar. ${ }^{7}$ Although the majority of patients remain asymptomatic, a considerable number experienced serious complications, including bowel obstruction, ${ }^{8}$ female secondary infertility, ${ }^{9}$ and reoperative complications. ${ }^{10}$ The presence of adhesions from previous surgery significantly increases the length of time required in subsequent surgical procedures, adversely affecting the workloads of surgical teams. ${ }^{11}$ Certain surgical procedures carry a greater risk of adhesionrelated complications. Surgical procedures on the ovary and fallopian tube were shown to have the highest risk of adhesion-related readmission ( 48.1 and $41.2 \%$ of women readmitted respectively). ${ }^{12}$ For laparoscopic myomectomy, this increases to 41 in every 100 procedures. ${ }^{13}$ In one study, the number of adhesion-related readmissions increased steadily over a 10 -year period; $16 \%$ of these readmissions were in the first year. ${ }^{6,12}$

Antiadhesion agents can be divided into two ways of action:

1. Site-specific agents

2. Broad coverage fluid agents

\section{Site-specific Agents}

Membranes mechanical barriers Interceed ${ }^{\circledR}$ (Gynecare, Ethicon, a Johnson and Johnson Company, Sommerville, New Jersey, USA): Interceed ${ }^{\circledR}$ is an oxidized regenerated cellulose membrane placed over a suture or a deperitonealized area. No sutures are required to keep Interceed ${ }^{\circledR}$ in place; slight moistening after positioning a single layer will make it adhere to the injured site, where it is absorbed within 4 weeks. Interceed ${ }^{\circledR}$ has been shown to be effective in various studies, and significantly reduces adhesion formation even in severe endometriosis. ${ }^{14}$

Seprafilm ${ }^{\circledR}$ (Genzyme, Cambridge, Massachusetts, USA): Seprafilm ${ }^{\circledR}$ is a hyaluronate-carboxymethyl cellulose membrane, which is placed over a suture or an injured area without stitches and remains in place for 7 days. In contrast to Interceed ${ }^{\circledR}$, no loss of efficacy in the presence of blood has been reported. Several studies have demonstrated the efficacy of Seprafilm ${ }^{\circledR}$ mainly in general surgery, especially bowel surgery. ${ }^{15}$

Gel barriers SprayShield/SprayGel ${ }^{\circledR}$ (Covidien BioSurgery, Waltham, Massachusetts, USA): SprayShield ${ }^{\circledR}$ is a synthetic polyethylene glycol solution which is sprayed 
over the affected area where it remains for at least 6 days before it is secreted through the kidney. Only after that period it is absorbed and degraded. It consists of two components that react immediately on contact with the tissue to form an adherent layer. One of the components contains a blue food colorant, so there is an intraoperative visualization of where SprayShield ${ }^{\circledR}$ was used. ${ }^{16,17}$ For SprayGel ${ }^{\circledR}$ in a multicenter randomized controlled study of myomectomies, a reduction of adhesions was demonstrated.

Intercoat ${ }^{\circledR} /$ Oxiplex/AP (FzioMed, Inc., San Luis Ob-ispo, California, USA): Intercoat ${ }^{\circledR}$ is an absorbable gel composed of polyethylene oxide and sodium carboxymethyl cellulose. Functioning as a mechanical barrier during the healing process, Intercoat ${ }^{\circledR}$ is applied as a single layer at the end of the procedures.

Hyacorp Endogel (Bio Science, Germany) is an absorbable sterile, transparent, high viscous gel produced by condensation of hyaluronic acid, which is one of the main components of human connective tissue. It adheres to tissue surfaces and to the abdominal wall and is effective as an antiadhesion barrier substance on the local level. The development of Hyacorp Endogel is based on a composition of a substance that already exists for treating and filling tissue defects (Hyacorp Body Con-touring MLF 1).

Hyalobarrier Gel ${ }^{\circledR}$ (Fidia Advanced Biopolymers, Ab-ano Terme, Italy): Hyalobarrier Gel is a highly viscous auto-crosslinked hyaluronate used to separate organs and tissues after surgery. The use of hyaluronic acid agents may decrease adhesion formation and prevent the deterioration of preexisting adhesions. ${ }^{18}$

CoSeal $^{\circledR}$ (Baxter Health care Corporation, Deerfield, Illinois, USA): $\mathrm{CoSeal}^{\circledR}$ is a resorbable hydrogel consisting of two polyethylene glycol polymer solutions which are mixed together when applied during surgery. The technology is similar to that seen with SprayShield ${ }^{\circledR}$ but in $\mathrm{CoSea}^{\circledR}{ }^{\circledR}$ the polyethylene glycol esters have a different isomer structure. CoSeal ${ }^{\circledR}$ is long available for preventing adhesions in cardiac surgery where its efficacy has already been proved. First, researches in women undergoing myomectomy demonstrated safety and efficacy of CoSeal ${ }^{\circledR}$ in abdominopelvic surgery. ${ }^{19}$

Broad-coverage Fluid Agents Adept ${ }^{\circledR}$ (Icodextrin 4\% solution; Baxter Health care, Deerfield II, Texas, USA): Adept $^{\circledR}$ is a clear solution containing icodextrin at a concentration of $4 \%$. Icodextrin is a 1 to 4 -linked glucose polymer and is responsible for the longer absorption time of Adept ${ }^{\circledR}$ compared with the previously used crystalloid instillates-like saline solution or lactated Ringer's solution, which is rapidly resorbed by the peritoneum and therefore not suitable for adhesion prevention. At the end of the procedure, 1,000 mL of Adept ${ }^{\circledR}$ is instilled into the abdominal cavity. Instillates separate the injured tissue by hydroflotation and should stay in the abdominal cavity during the first day after surgery.

In laparoscopic hysterectomies out of the available pellet of adhesion prevention strategies, we advise at present time the application of a site-specific barrier either on hyaluronic acid basis (HyaCorp Endo Gel; Bioscience or Hyalobarrier; Nordic Pharma) and in case of a large peritoneal defect results a broad liquid barrier icodextrine $-4 \%$-Adept-Baxter.

\section{Meshes}

There are many new kits on the market that involve the placement of the same nylon-like mesh in the tension-free vaginal tape, but instead used in large sheets between the bladder and the vagina and the rectum and the vagina to reinforce prolapse repair. There is no long-term information on these techniques. Therefore, we will hold off promoting or criticizing these techniques until there is adequate information available. As these materials are permanent, there is always a benefit in waiting to see the long-term complications before jumping onto the bandwagon of laparoscopic mesh application in sacrocolpopexy or the new technique of prolapse surgery pectopexy after laparoscopic hysterectomy, as the longterm complications may include mesh erosion into the vagina, bladder or rectum, painful intercourse, infection or bleeding, etc.

\section{Suture Ligatures and Suturing Techniques}

Suture ligatures and suturing techniques are besides all the modern coagulation advances. Many times, these are really necessary for safe surgery in hysterectomy. Therefore, we would like to give some basic idea on hemostasis by loop ligatures, endosutures with extracorporeal knotting technique, and endosutures with intracorporeal knotting technique.

\section{Hemostasis by Endosuture with Extracorporal Knot Tying}

In many cases, it is convenient to ligate vascular bundles, adhesion bundles, and similar structures with sling ligatures. Timewise, it is worthwhile to tie the vascular omental and intestinal adhesions before cutting because searching for bleeders later can be time-consuming and associated with much blood loss. Primarily, an $80 \mathrm{~cm}$ long Ethi-Endoligature ${ }^{\circledR}$ with a plastic knot pusher by Ethicon is used as a ligature. As an endosuture, it has a $3 \mathrm{~cm}$ long and $0.8 \mathrm{~mm}$ thick needle. The endosuture with extracorporeal knotting has a 2.5 and $3.5 \mathrm{~cm}$ long sharp needle as well as a $2.5 \mathrm{~cm}$ round needle. It is supplied with a suture applicator and a $3 \mathrm{~mm}$ trocar by Autosuture. After taking 
a purse string suture, the needle is cut; extracorporeal knots are fashioned and pushed down in the usual way with the plastic pusher (Figs 2 to 6). To push the knot, the applicator is pulled up. When it is pushed again into the $5 \mathrm{~mm}$ trocar, the plastic tube pushes the knot into the abdominal cavity. The loop is tightened under vision and the wound edges are adapted, e.g., the wound edges of the vaginal cuff. Cutting scissors are inserted in place of the $5 \mathrm{~mm}$ needle holder to cut the thread. The thread must be long enough to be able to fashion extracorporeal knots outside.

\section{Hemostasis by Endosuture with Intracorporeal Knotting}

For intracorporeal knotting, a straight or curved needle with different suture calibers is used. For microsurgi-

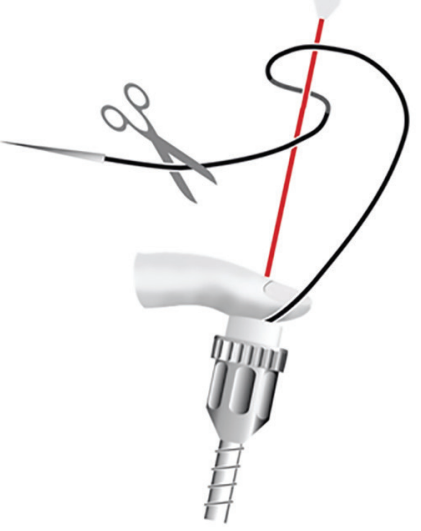

A

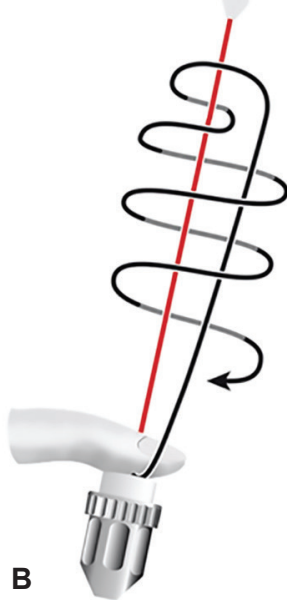

B
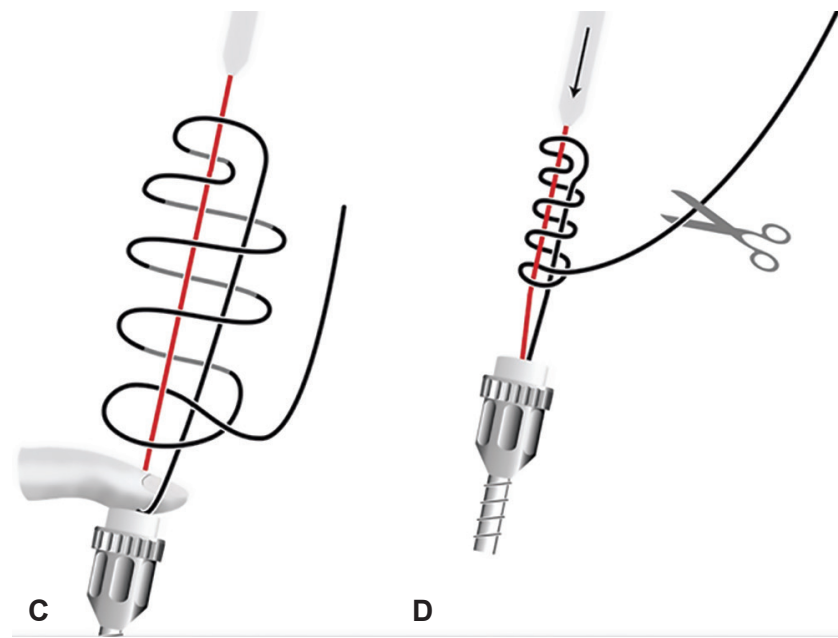

Figs 2A to D: Roeder knot: (A) Pull out the suture, remove the needle half hitch around the post strand; (B) throw three loops around both strands. Maintain tension; $(C)$ half hitch around the post strand (red); push the knot together; and (D) shorten the suture to approx. $2-3 \mathrm{~cm}$ and perform intra-abdominal safety knot

A

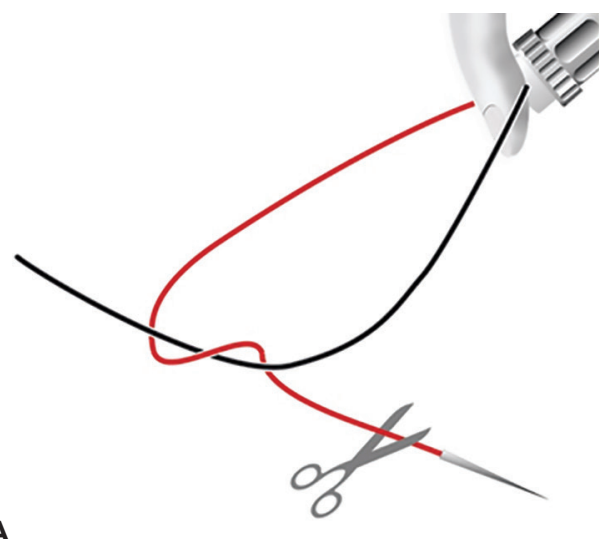

C

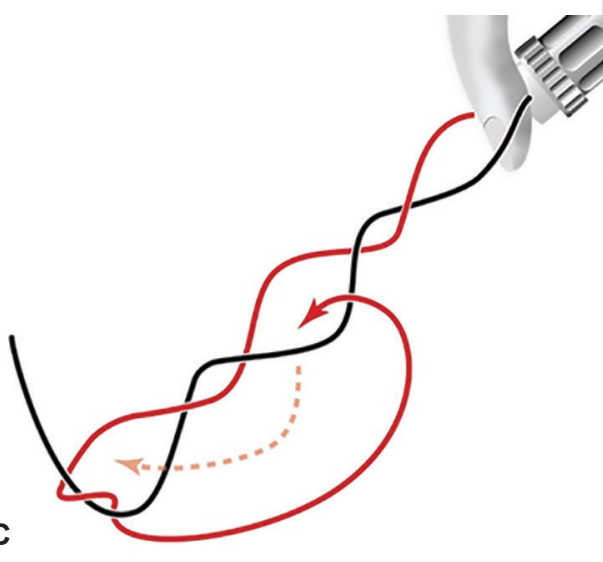

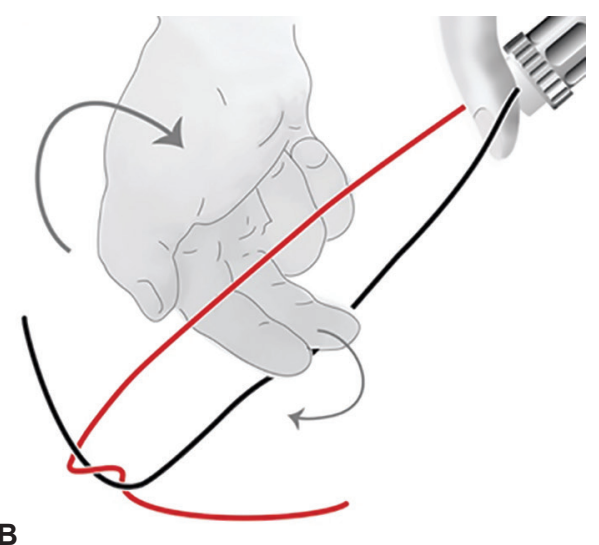

B

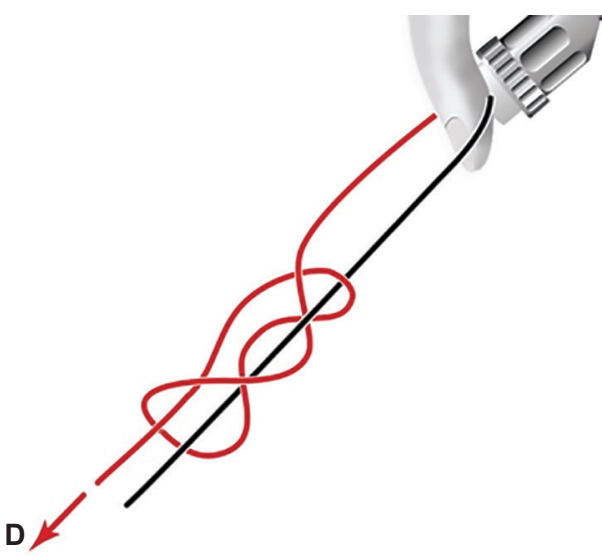

Figs 3A to D: von Leffern knot: (A) Pull out the suture, remove the needle, half hitch; (B) hold the knot with the left hand and reach over with the right hand; $(C)$ grasp the short end from below and lead it back, exiting before the half hitch; and (D) turn back the knot. Hold the straight suture and tighten the knot 


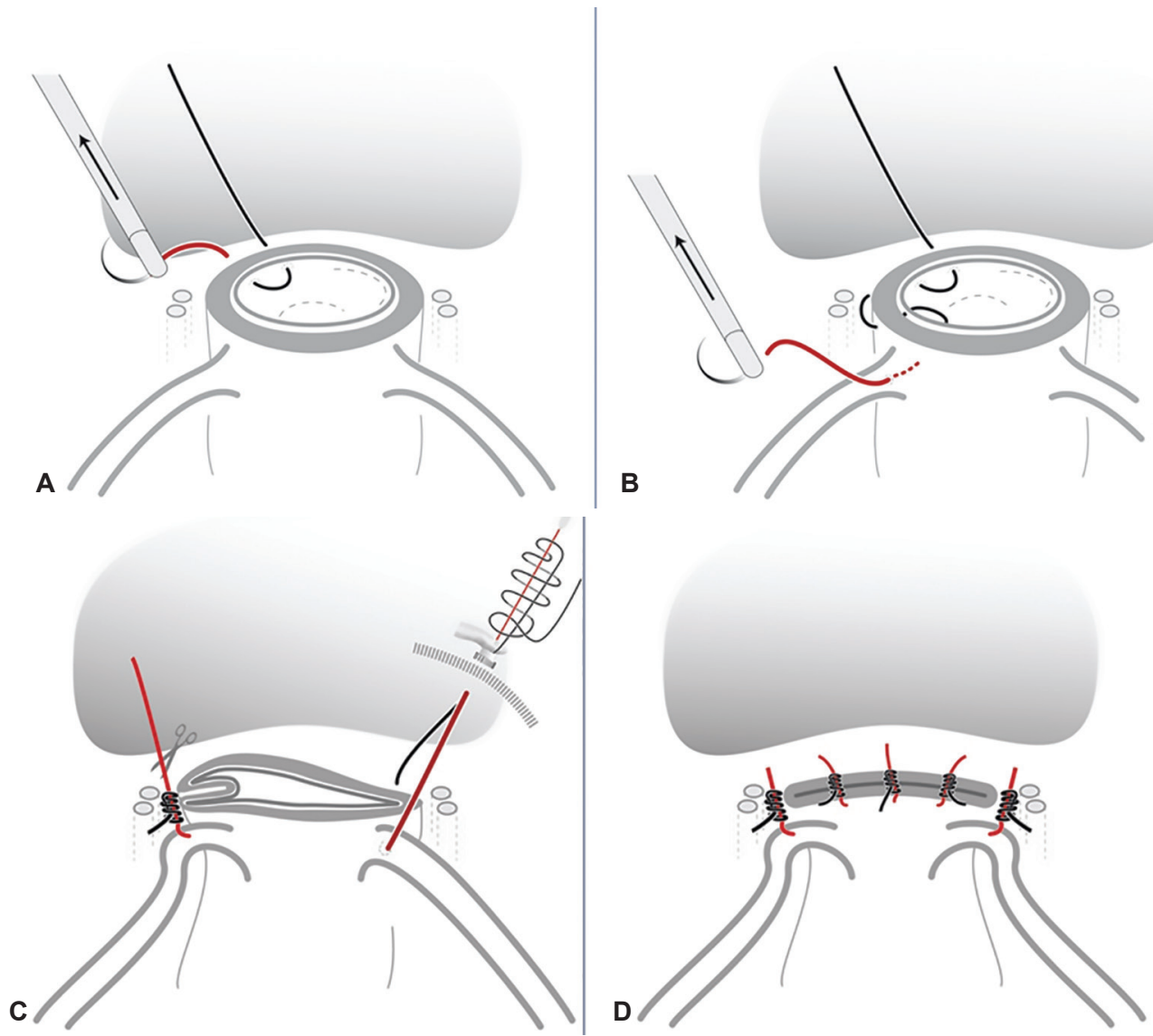

Figs 4A to D: Vaginal closure for descent prevention Te Linde adapted by van Herendael: (A)A vicryl suture CT 1 plus needle is passed through the endopelvic fascia and $1 \mathrm{~cm}$ below the cephaled edge of the vaginal epithelium; (B) the needle is pushed from the vaginal lumen through the vaginal wall, passed between the uterine vessels (median part of the broad ligament) and brought back through the vaginal lumen; $(\mathrm{C})$ the sacrouterine lig. is identified before the suture is passed through. The needle is pushed from the vaginal lumen through the vaginal wall, rectovaginal septum and transpierces the sacrouterine ligament; and (D) closure of the vaginal vault with single stitches. Again, the stitch is drawn through the endopelvic fascia—vaginal wall—vaginal wall—rectovaginal septum

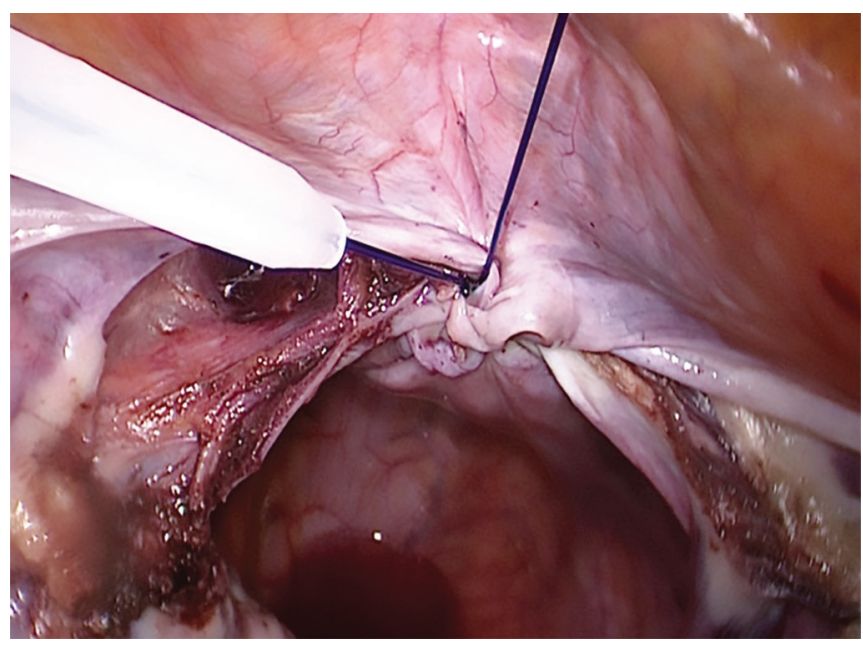

Fig. 5: After having formed the knot extracorporally, it is pushed down with the plastic knot pusher

cal interventions, such as end-to-end anastomosis of the tube, 4-0 to 6-0 sutures are used, otherwise 1-0 is adequate for vaginal cuff suture. The long-end of a thread, originally knotted extracorporeally, is wrapped around the needle holder twice, while the needle holder

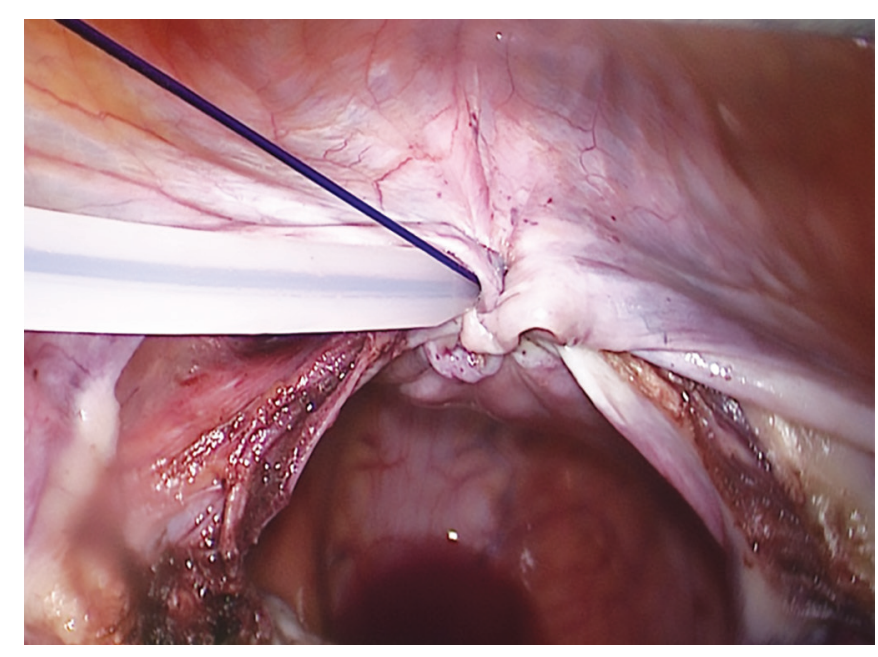

Fig. 6: To tighten the knot, the other end of the thread is held with some tension, while the knot pusher is pressed onto the knot firmly

is aiming for the short end of the thread to perform an additional, intracorporeal safety knot (Fig. 7). Among many other intracorporeal suturings, the baseball suture is especially suitable to compress wounds, e.g., after enucleation of myomas. 

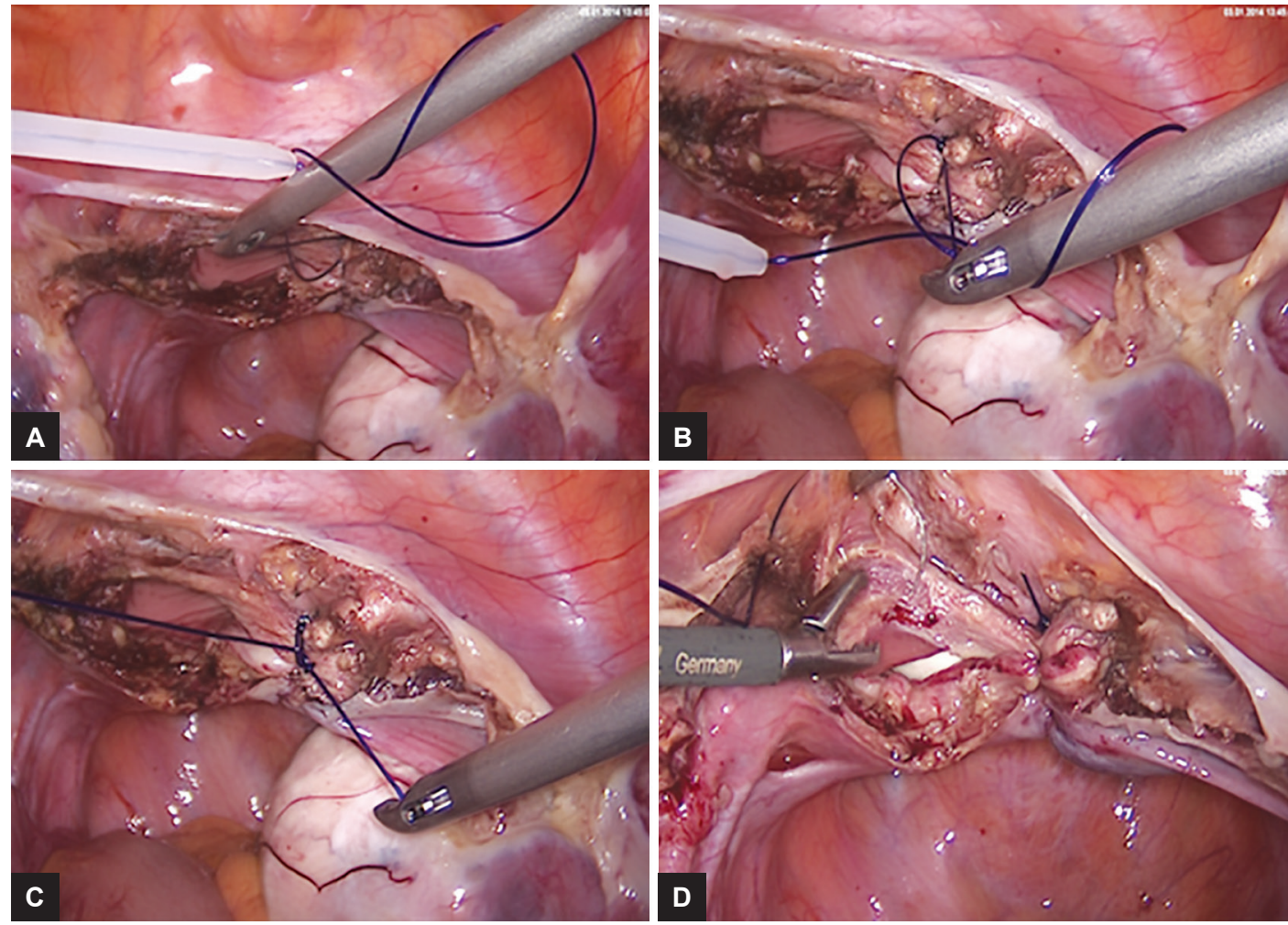

Figs $7 \mathrm{~A}$ to $\mathrm{D}$ : Intracorporal knot to give final tension

Due to this technique of suturing, the size of the wound is minimized and along with it the risk of immediate and later bleeding. In addition, the occurrence of adhesions is reduced since the wound is closed toward the surrounding tissue. Stitching and tying of the whole uterine vessel bundle requires good knowledge of anatomy.

\section{Hemostasis by Suture and Tying Knot with Half-hitch}

The Clark knot pusher is used for this procedure. With the extracorporeal thread, a half-hitch is formed and the knot is then pushed down with the knot pusher.

\section{Staples and Stapling Instruments}

A safe way for vessel occlusion at laparoscopic hysterectomies is provided by "ENDO GIA" These ENDO GIAs are available with straight and curved tips. The unique ENDO GIA $^{\mathrm{TM}}$ curved tip reload with Tri-Staple ${ }^{\mathrm{TM}}$ Technology of COVIDIEN is a stapler designed with a curved tip at the distal end of the anvil to provide enhanced visibility and maneuverability around target tissues and vessels.

\section{Tissue Glues}

A variety of adhesive substances can be applied locally during laparoscopic hysterectomy for hemostasis or wound closure. The main classes of tissue adhesives are cyanoacrylate glues, fibrin glue, and thrombin. Cyanoac- rylate glues are widely used in gastrointestinal endoscopy for control of bleeding from gastric varices and, to a much lesser degree, for hemostasis of bleeding peptic ulceration, and for closure of fistulas and anastomotic leaks. Fibrin glue (fibrinogen and thrombin) and thrombin have been used extensively in all surgical disciplines for tissue adhesion, suture support, hemostasis, wound care, and the sealing of body cavities, including the subarachnoid space.

Biosurgical agents designed to promote tissue adhesion and hemostasis are being increasingly employed also in hysterectomies. Fibrin sealant is the most widely utilized biosurgical product. Gelatin matrix thrombin has proven to be an efficacious hemostatic agent. Bovine serum albumin-glutaraldehyde is a new promising tissue glue.

\section{INSTRUMENT SYSTEMS AND APPARATUSES FOR LAPAROSCOPIC HYSTERECTOMIES}

\section{Conventional Laparoscopy}

\section{General Aspects on Instrumentations}

Out of the many instruments available today for hysterectomies, we describe here only a few which are really necessary to be available in duplicate or triplicate on the instrument trolley. Multiple use of instruments for cutting, grasping, dissection, pushing, traction, coagulation, irrigation, and suction are very helpful.

Instruments for perforation, suction, irrigation, and needle holders have to be always there. 
- The Veress needle is blindly introduced into the abdomen after lifting the anterior abdomen wall. ${ }^{20}$ Trocars of 3, 7, 10, 12, 15, 20, $24 \mathrm{~mm}$ diameter are used for guiding the endoscopes and operative instruments, irrigation, coagulation, and during employment of needle holders and morcellators.

- The simple automatic flap valves can leak at blood contamination or tissue particles blockage, allowing them to be used for single application only. Trumpet valves are solid but must always be opened and closed. They hinder the introduction of needles and thread.

- Endoscopic lenses must be frequently washed and removed because of soiling during the operation. Therefore, for such trocars, we reluctantly use automatic valve, but prefer trumpet valve.

- Primary trocars can be inserted by the Z-puncture technique to prevent dehiscence of aponeurosis and late omentum prolapse. The right decision must be done by the surgeon. Conical and pyramidal trocars are recommended. Pyramidal trocars carry the advantage of sharp cutting edges-OptiviewREthicon (Ethicon Endo-Surgery, Cincinnati, USA), Visiport R Covidien (Mansfield, Massachusetts, USA), and XCel Ethicon (Fig. 8) offer insertion under vision. At present, only 10 to $11 \mathrm{~mm}$ trocars are available through which the $10 \mathrm{~mm}$ laparoscope can be passed under direct vision.

- The entry of the optical trocar can be inserted under vision but one looks still through a plastic layer. The insertion under vision can also be done below left costal margin; a suitable trocar can inserted through the umbilicus under vision.

- The linear expansion trocars help controlled widening of a narrow canal by serial dilatation.

- The Endo-Tip is the only available trocar which is really inserted under direct vision (Fig. 9).

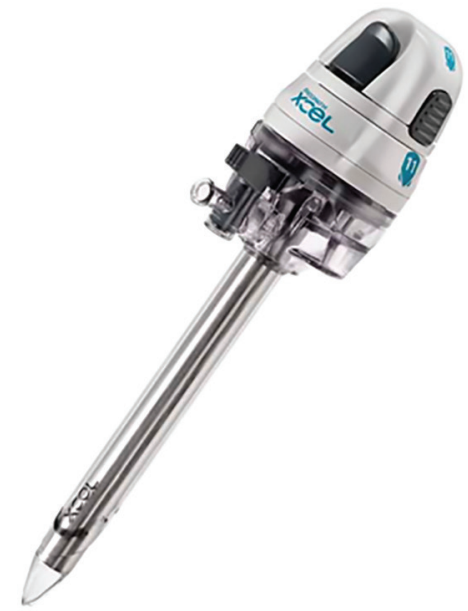

Fig. 8: Endopath Xcel bladeless trocar (Ethicon)
Dilatation instruments: It is possible to dilate up to $10,12,15$, and $20 \mathrm{~mm}$ through an introduced rod and a suitable $5 \mathrm{~mm}$ threaded trocar.

Holding, grasping instruments and screws: Various types of traumatic and atraumatic forceps are used as endoscopic grasping tools for laparoscopic hysterectomies. They are in 5 to $20 \mathrm{~mm}$ sizes. In $10 \mathrm{~mm}$ size, we recommend the big toothed forceps and lymph node holding forceps to hold the tissues firmly. The $10 \mathrm{~mm}$ swab holding forceps are suitable for holding tissues lightly and for pushing. The 5 and $10 \mathrm{~mm}$ swab holders are used in tissue dissection. The 5 and $10 \mathrm{~mm}$ myoma screw may be used for traction of the uterus. The handles of the Robi instruments of the Karl Storz Company are easier and more ergonomic to use (Fig. 9) than older round-grip handle versions.

Cutting instruments: $5 \mathrm{~mm}$ curved scissors and the $5 \mathrm{~mm}$ and the $11 \mathrm{~mm}$ saw-toothed scissors as well as different microknives with changeable disposable blades are available in the market. Mostly, curved scissors are used, but round scissors with electric connection are frequently employed because of their extreme safety. The latter one is often used as a disposable instrument.

Suction and irrigation instruments: The suction irrigation devices of Karl Storz, Olympus, Wolf, etc., are well known. The suction cannula is used either with an open tip or with a perforated tip. Large volumes of fluids are aspirated with these suction irrigation cannulas (Fig. 10). They are set at an irrigation pressure of up to $300 \mathrm{~mm}$ $\mathrm{Hg}$ and an aspiration force of up to 1 bar. The normal suction force is maximum 800 mbar; irrigation pressure is $300 \mathrm{~mm} \mathrm{Hg}$. With extra-long $(50 \mathrm{~cm})$ suction irrigation tubes, it is possible to suck even under the dome of diaphragm from the pelvic region. Many disposable systems are also available.

Morcellation instruments: The development of morcellation instruments was slow. In ovarian resection and

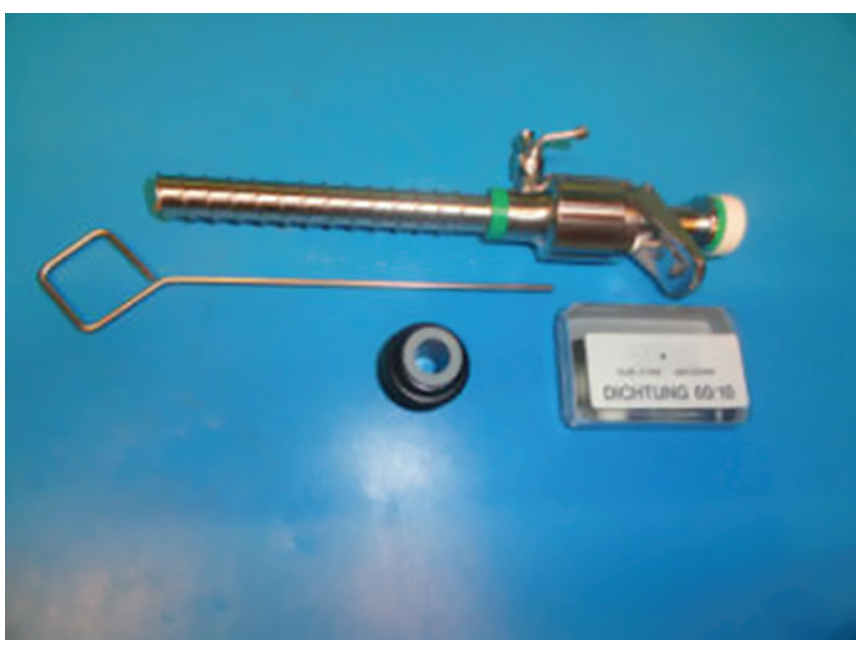

Fig. 9: Endo-tip (Storz) 


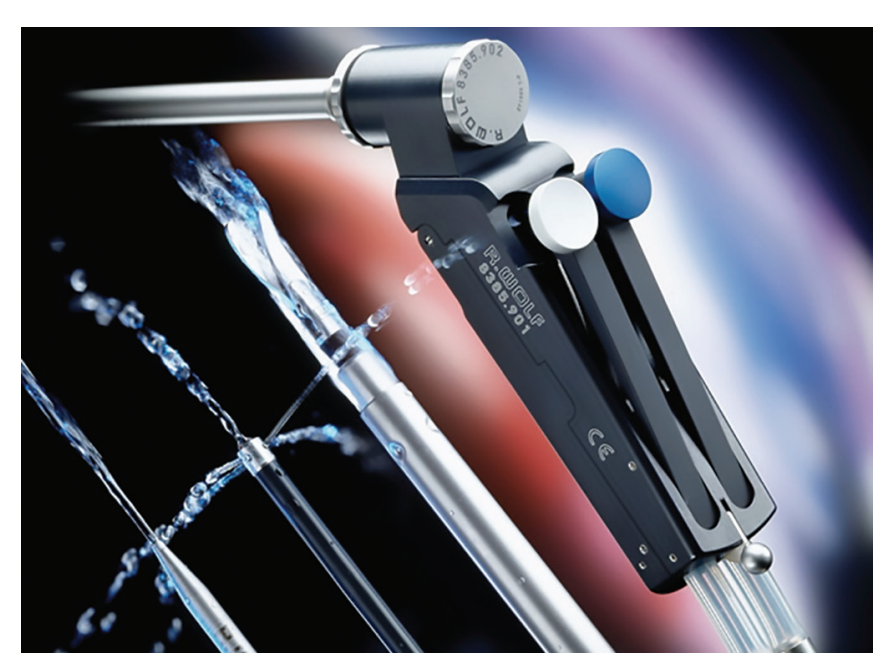

Fig. 10: Suction irrigation system (R. Wolf, Knittlingen, Germany)

enucleation of myoma, the tissue was cut with scissors and knives, depending on the size. The specimen can be removed either with big-toothed forceps or a big sponge holding forceps directly through the 11 or $15 \mathrm{~mm}$ trocar with conical end. However, the so-called motor drive morcellators in 10, 15, and $20 \mathrm{~mm}$ diameters are electrically powered and function well. The tissue is slowly cut electrically, nearly shaved from the surface, and pulled into the trocar sleeve. It is particularly suitable for horizontal operations as in vertical use a laceration of bowel or vessels can easily occur. Karl Storz produces the Steiner morcellator $^{\circledR}$, the Rotocut and a new development, the Sawalhe II Supercut morcellator, all with a tissue protection shield (Figs 11 and 12). In bag morcellation more and more being developed to prevent tissue particles being left in the abdominal cavity. Sarcomas should, of course, not be morcelllated and be recognized prior to hysterectomy and morcellation.

Many companies have disposable morcellators. The WISAP electric morcellator was the first on the interna-

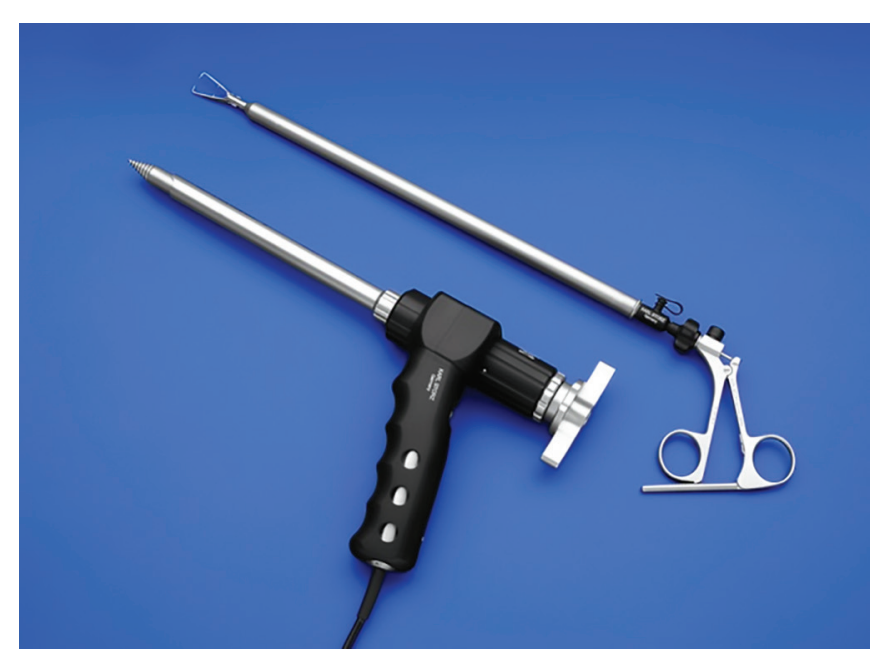

Fig. 12: Sawalhe II Supercut morcellator Morcellator (Karl Storz)

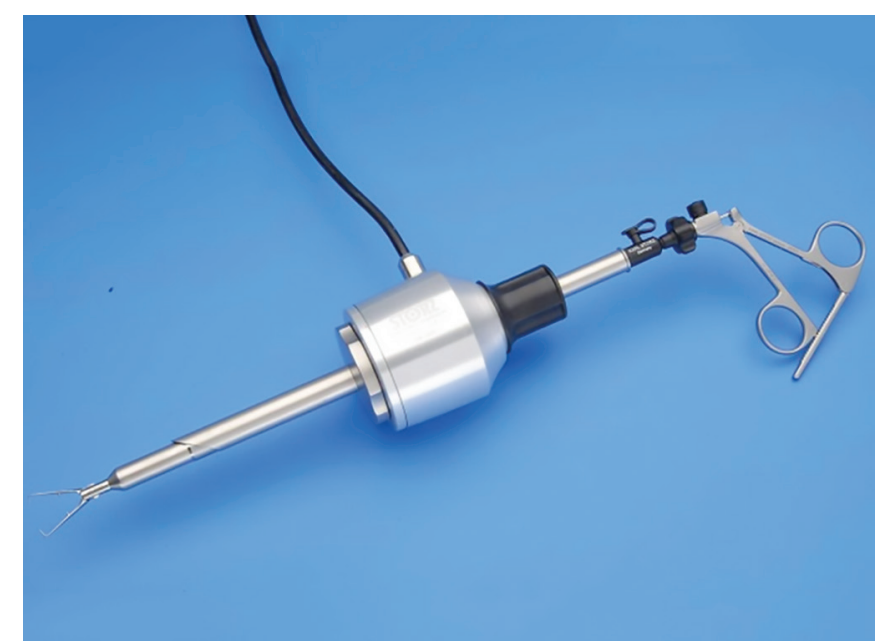

Fig. 11: Rotocut G1 (Karl Storz), morcellation tool with protective shield, available in two sizes (12 and $15 \mathrm{~mm}$ )

tional market. Alternatively, the surgical specimen from the abdominal cavity is put in an endobag (small plastic bags) with forceps. Morcellation is only advised at present for benign specimens. However, we foresee the transformation of fibroid-like material into powder, which can then be aspirated and examined by the molecular geneticistpathologist for malignancy. In case of uterine tissue, this would mean to detect mutations in these carcinosarcomas that are found in about 1 to 4 per thousand in myomas. Of course, any hysterectomy is preceded by careful imaging with ultrasound and often magnetic resonance imaging, where bulky polyploid masses with heterogeneous appearance and increased vascularity, lacking calcifications would lead the surgeon to avoid morcellation.

However, after the Boston case of a nonrecognition of a sarcoma at morcellation was published over all public media, everyone became more careful not to spread tissue at morcellation. Morcellation in bags became available and some companies have retracted their morcellation devices.

Instruments for hemostasis: Instruments for tying the blood vessels, such as the Roeder loop, the endoligature or the endosutures with extra or intracorporeal knotting are widely known. Needle holders for straight, curved, or Ski needles must be available in different variations.

For hemostasis, endocoagulation, heat denaturation at 100 to $1200^{\circ} \mathrm{C}$, bipolar coagulation in various forms (see section on energy sources in this chapter) and monopolar needle, melting hook, high-frequency (HF) scissors, or other instruments are suitable. ${ }^{21}$ For localized ischemia, a vasopressin derivative in a dilution of 1 to 100 is injected subcapsular with an applicator.

Gynecologists prefer suturing and coagulation devices. However, clips and stapling devices, which are more frequently used by general surgeons, are also used for fixing meshes, for pelvic floor surgery, lymphad- 


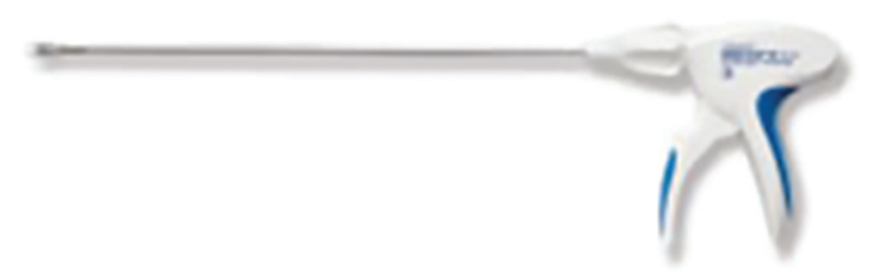

Fig. 13: Endo GIA ${ }^{\mathrm{TM}}$ ultra universal stapler (Covidien)

enectomy, and hysterectomy in our field. Both Ethicon, a Johnson and Johnson company (New Brunswick, New Jersey, USA), and Covidien have fascinating devices on the market. Let us just mention here Covidien's new Endo Clip Applicator III ( $5 \mathrm{~mm}$ ) with easy to be situated clips and a digital clip counter (Fig. 13) and the Endo GIA ${ }^{\mathrm{TM}}$ Stapler (Figs 14 and 15).

Instruments for clamping large vessels, emergency needle: Emergency instruments and usual clamps used in routine gynecological operations should not be used for clamping the vessels. Vascular clamps must be readily available. Large vessel injury must be immediately explored by laparotomy and the bleeding vessel clamped. If a vessel in the anterior abdominal wall is injured (epigastric artery), it is advisable to ligate it at an appropriate place with a large emergency needle.

Instruments for drainage: The Robinson drainage is suitable for abdominal drainage. It works on a gravity basis and as a rule can be left in situ over 24 hours.

Instruments for uterine manipulation: Vacuum intracervical probes in the standard three sizes allow only partial movement of the uterus and facilitate tubal chromopertubation.

Various instruments for intrauterine manipulation make it possible to move the uterus in side-to-side, ante and retroflexion as well as rotation movements and sometimes allow the possibility of chromopertubation.
Uterine manipulation is required in endometriosis of the pouch of Douglas, for hysterectomies, in bladderdome endometriosis and for enucleation of myoma. The Abdominal Cavity Expander serves to elevate the anterior abdominal wall in cases with adhesions. Further versions of this principle are used in the gasless laparoscopy, e.g., as Laparolift ${ }^{\circledR}$.

The Hohl, the Mangeshikar, and the Donnez intrauterine manipulators or mobilizers as well as the Konincxk uterine twister are all produced by Karl Storz and have a cup with a well palpable and visible border to visualize the resection level between vagina and cervix for all cases of total laparoscopic hysterectomy (TLH) (Fig. 16). This facilitates the intracervical approach of TLH; however, they are not to be used for the extracervical approach and in oncologic cases of hysterectomy. Many companies have disposable manipulators.

Lenses and endoscopes: Scopes are available in rigid and flexible systems (Fig. 17). The rigid system is based on Hopkins's experience with a rod lens system, which results in good resolution and depth of focus ratio. ${ }^{22}$ Flexible endoscopes are based on the use of optical fiber bundles. The rigid laparoscopes are in 3 to $11 \mathrm{~mm}$ sizes, e.g., the arthroscope with a $140^{\circ}$ angle. Most of the rigid endoscopes are directly connected to the telescope through the camera coupling system. The picture is enlarged so that it looks even bigger on the monitor. In flexible endoscopes, the bundle of fibers is also enlarged. The standard laparoscopes are rigid instruments with a 00 lens. The 300 lens has the advantage of a wide panoramic view. With the ENDOCAMELEON (Karl Storz), a $120^{\circ}$ panoramic view is possible (Fig. 18).

Each camera has two components: head and control. A $35 \mathrm{~mm}$ coupling system yields a much more enlarged picture than a $28 \mathrm{~mm}$ coupler. A direct coupling transmits the picture directly to the camera.
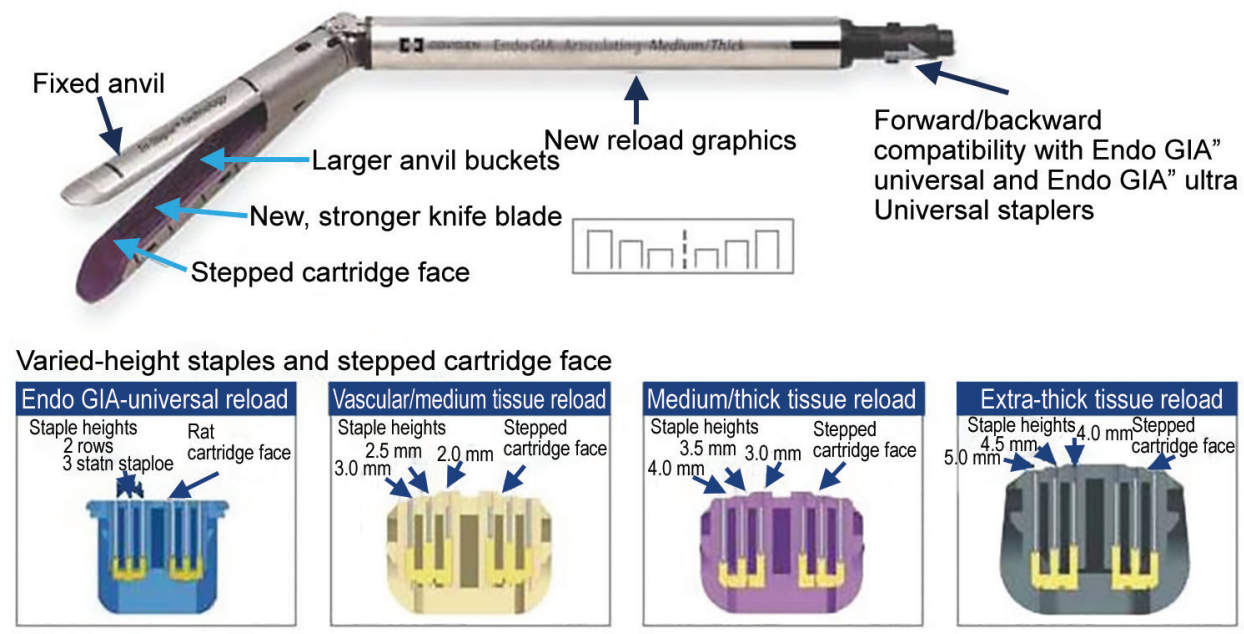

Fig. 14: Endo GIATM reloads with Tri-Staple ${ }^{\mathrm{TM}}$ technology (Covidien) 


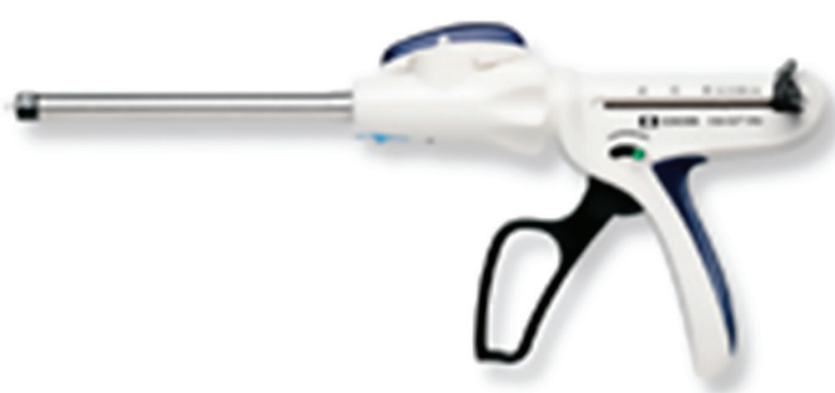

Fig. 15: Endo GIA ${ }^{\mathrm{TM}}$ ultra universal stapler (Covidien)
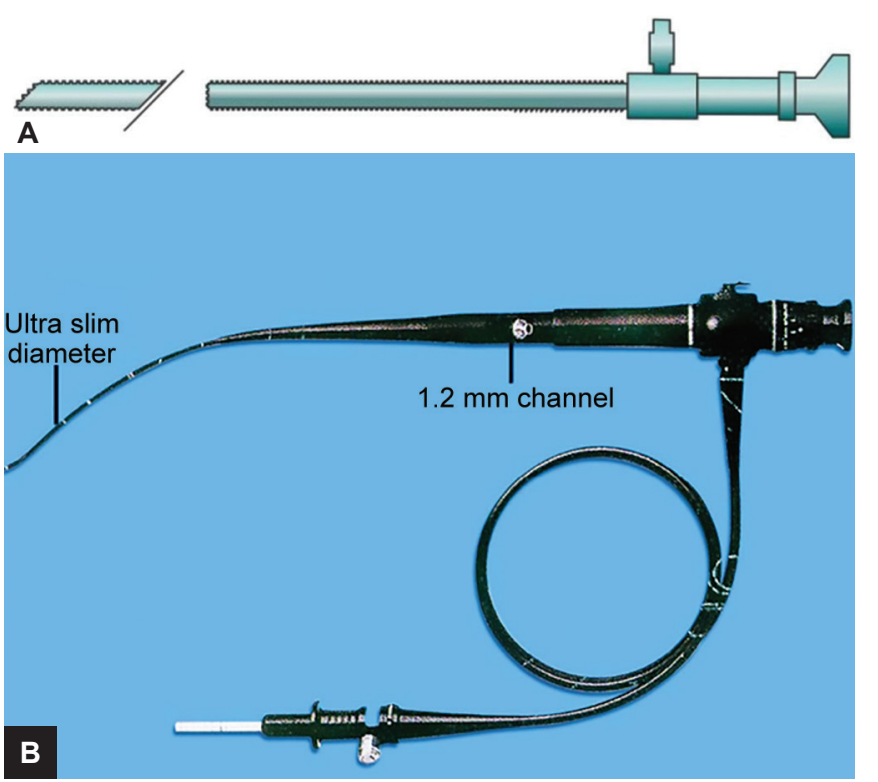

Figs 17A and B: Endoscopes: (A) Rigid standard laparoscope $(10 \mathrm{~mm})$ with $30^{\circ}$ optic and with $0^{\circ}$ optic; (B) flexible endoscope

Olympus Surgical (Hamburg, Germany) offers different flexible endoscopes as well as rigid endoscopes with flexible tips with four directions and a $100^{\circ}$ bendable performance as chip on the tip (Fig. 19). With the chip on the tip of the optic, the observation light passes through fewer lenses than on a rigid scope. This allows brighter and sharper images than when the camera is attached to the head of the optic.

\section{Energy Systems for SLH, TLH, and Radical Laparoscopic Hysterectomies (Electrosurgery and Thermofusion)}

Electrosurgery: Electro section, i.e., cutting of tissue between the active electrode and the tissue where an electrical arc is generated, takes place above $2000^{\circ} \mathrm{C}$. During coagulation and desiccation, the tissue is heated slowly. It results in denaturation, evaporation of water, and secondary hemostasis. The argon beam coagulator is a monopolar electrosurgical instrument. In principle, noncombustible argon gas $(4 \mathrm{~L} / \mathrm{min})$ across an electrode cannula acts as a bridge for electrical current to burn the tissue superficially (up to $5 \mathrm{~mm}$ depth). ${ }^{23}$ As the gas is

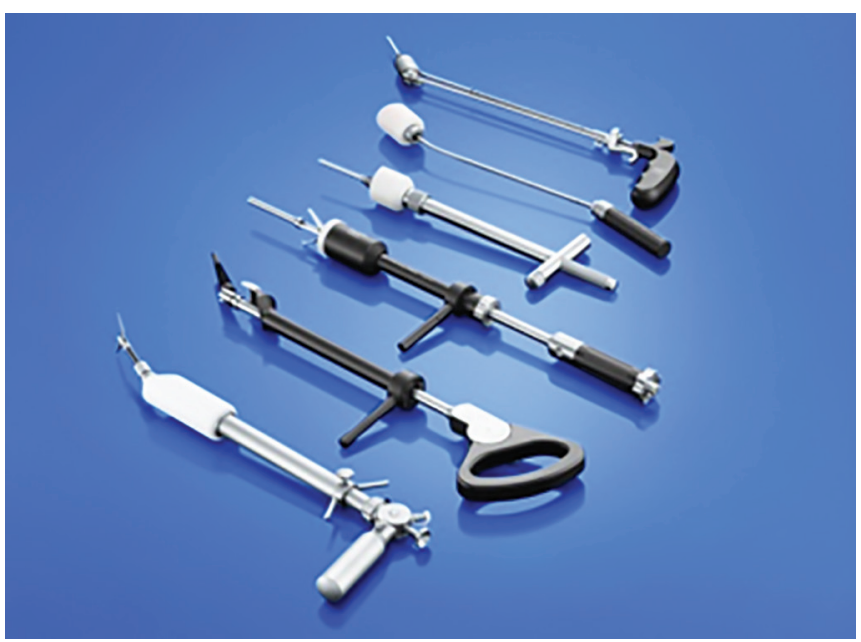

Fig. 16: Intrauterine manipulators produced by Karl Storz according to Koninckx, Clermont-Ferrand, Mangeshikar, Hohl, Donnez and Tintara

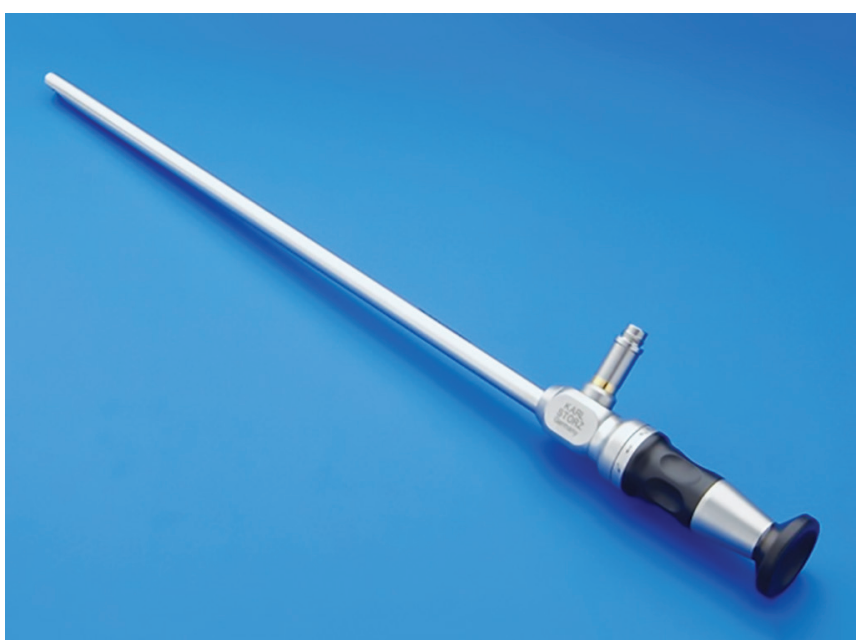

Fig. 18: ENDOCAMELEON ${ }^{\circledR}$ laparoscope (Karl Storz)

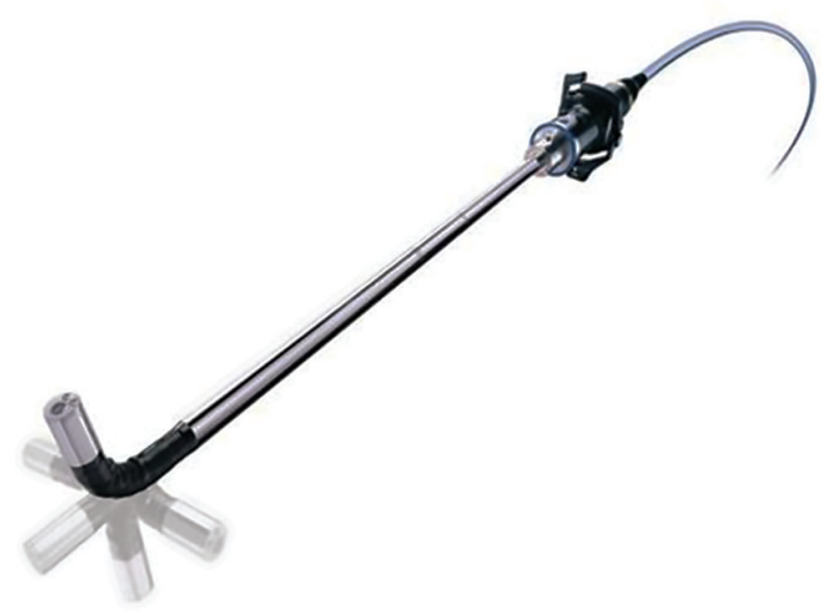

Fig. 19: EndoEYE video laparoscope (Olympus)

easier to ionize than air, electrical arcs develop up to 1 $\mathrm{cm}$ above the tissue surface. In monopolar electrosurgery, high-density current is used at the active electrode that is conducted to the patient on touching. In bipolar electrosurgery, two small electrodes of same size are 


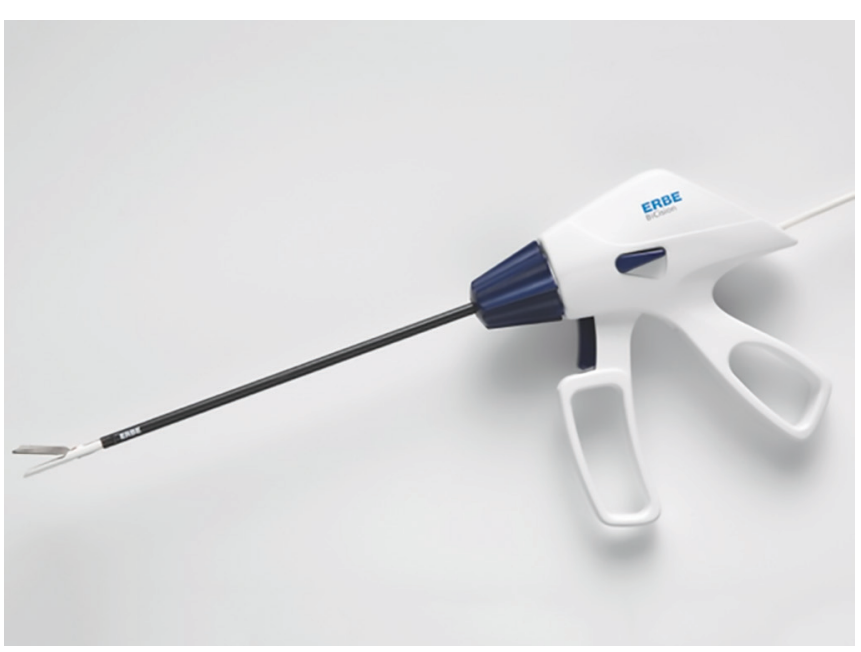

Fig. 20: BiCision coagulation and cutting forceps (Erbe)

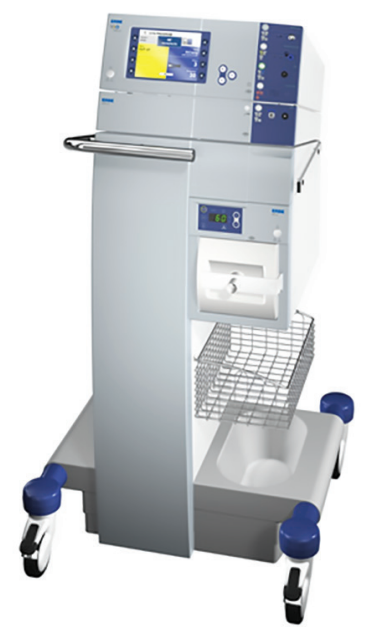

Fig. 21: Erbe gynecological workstation VIO 300 D used, which lie close to each other and function as active passive electrodes.

While the use of thermal hemostasis goes back to the glowing iron, according to Paquelin, the development of safe HF current techniques took 40 years. The application of the laser technique, ultrasonic cutting and coagulation techniques, and the local thermal effects, such as thermocoagulation, take place in the range of 80 to $1200^{\circ} \mathrm{C}$. Suturing and clip techniques are handled in next section.

We differentiate between fulguration and coagulation in HF hemostasis. In fulguration, electromagnetic oscillations across an air bridge produce radio frequency between the tip of the electrode and the surface of the organ, i.e., they come in direct contact. The generated heat is limited to tissue surface, i.e., the area visible through the scope. By coagulation we mean the heating of the tissues until intracellular water boils under the influence of HF current.

In addition to the technique used for fulguration and for coagulation, the most important technique in medicine and endoscopic surgery is the electrotomy, the cutting of tissue with the so-called electrical knife or the electrical loop.

At present, even with HF instruments there is no blind and uncontrolled burning because of the electrical system control. Therefore, we use monopolar current for cutting and bipolar instruments when coagulation is required before cutting big vessels in endoscopic surgery. Most of the systems have an autostop, so that only the required tissue is denatured. It is not set for a very big coagulation zone. Bi-Clamp for vaginal and open surgery and BiCision (Fig. 20) for laparoscopic surgery are the thermofusion devices of Erbe Elektromedizin $\mathrm{GmbH}$ (Tübingen, Germany). Their effect is an electronically controlled thermofusion and the mechanical separation of tissue.
The electrocoagulation system of Erbe (Fig. 21) uses an additional argon beamer, controlled by a foot switch, which facilitates linear coagulation by switching on the argon gas. This gynecological workstation with the HF module VIO $300 \mathrm{D}$ can be connected to any monopolar or bipolar coagulation device. It contains several modules, such as the argon plasma coagulation (APC 2) and the smoke plume evacuator (IES 2). The Erbe electrosurgical unit (ESU) has a color monitor display that provides the user with an on-screen tutorial as well as settings and operational information. The unit has various cutting and coagulation modes with defined effect levels to provide the physician flexibility in interventional applications (i.e., its ability to generate HF current). The system has automatic start and stop features. The equipment is programmable and various accessories (e.g., footswitches, hand instruments, etc.) as well as modes may be assigned to perform specific functions. Upon activation, the energy delivered (in watts) from the ESU to the tissue is displayed on the display screen.

Bipolar vessel sealing, also described as thermofusion, combined with pressure between the branches of the instruments, is a new, easy to use technique that has been picked up by many companies in the production of disposable instruments with integrated cutting devices, such as LigaSure (Covidien) (Figs 22 and 23).

The Nightknife (BOWA-electronic $\mathrm{GmbH}$, Gomaringen, Germany) (Fig. 24) is a bipolar vessel sealing device. The instrument incorporates atraumatic tips for secure dissecting and sealing. The integrated cutting system saves changing instruments for tissue separation.

The Gyrus PK (Olympus) technology delivers a proprietary, pulsing ultra-low $(110 \mathrm{~V})$ and high-current RF energy waveform to create a broad range of tissue effects, and allows the tissue and device tip to cool during the "energy off" phase, minimizing sticking and charring (Fig. 25). 


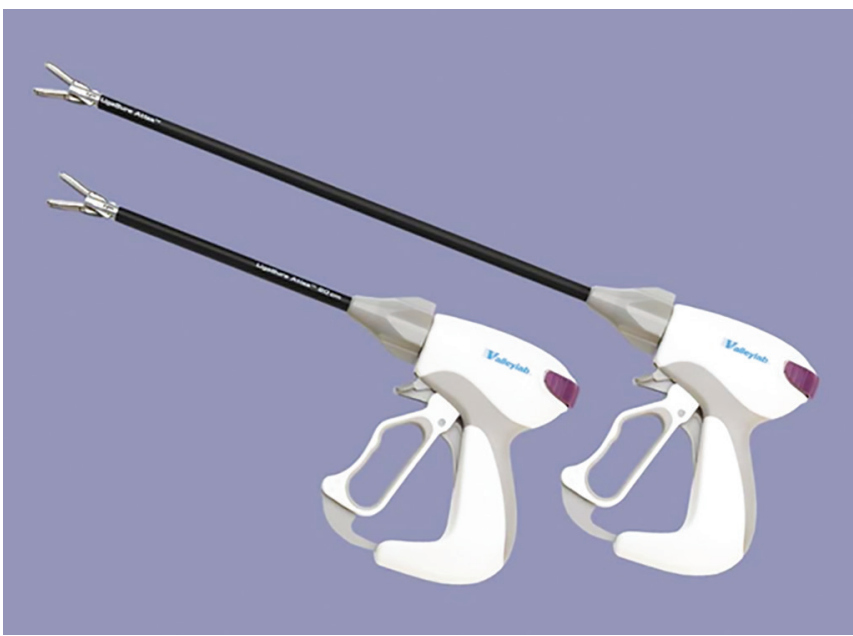

Fig. 22: LigaSure (Covidien), bipolar vessel sealing system, $10 \mathrm{~mm}$ (Atlas) and $5 \mathrm{~mm}$

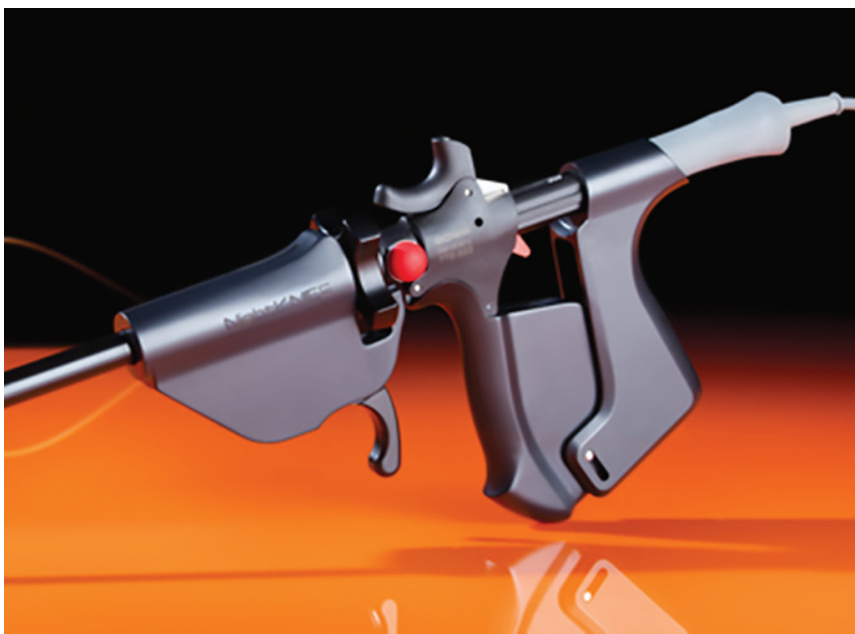

Fig. 24: Nightknife (BOWA-electronic)

By means of the smart electrode technology, the ENSEAL sealing instrument (Ethicon Endo-Surgery) permits simultaneous sealing and the possibility of tissue separation, including vessels up to $7 \mathrm{~mm}$ (Fig. 26). The tip

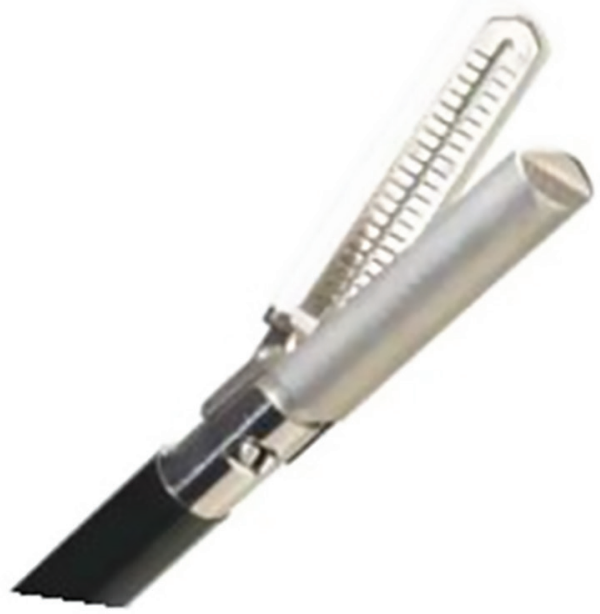

Fig. 23: LigaSure (Covidien) jaw providing a combination of pressure and energy to create vessel fusion

of the instrument has either a $5 \mathrm{~mm}$ round tip or a $3 \mathrm{~mm}$ slightly curved tip, enabling tissue preparation and sealing.

Laser: Laser beam is often described as "light that heals." Laser is acronym for Light Amplification by Stimulated Emission of Radiation. Fox established the first surgical laser in 1960. Bruhat and his colleagues in 1979 and Tadir and colleagues in 1996 introduced $\mathrm{CO}_{2}$ laser in laparoscopy. Today, there are enthusiasts of laser surgery and enthusiasts of electrosurgery. Light energy is amplified to generate increased coherent electromagnetic radiation. Here we mention the three forms of laser used in endoscopic surgery:

1. $\mathrm{CO}_{2}$ laser

2. Nd:YAG laser

3. KTP lasers

The neodymium:yttrium-aluminum-garnet (Nd:YAG) laser, the argon laser, and KTP (potassium-titaniumphosphate) lasers are used for cutting and coagulation. All the tissue effects are produced because of the continuous or pulsing thermodynamic conversion of light in thermal energy. Because of the 150 refraction of the laser beam after
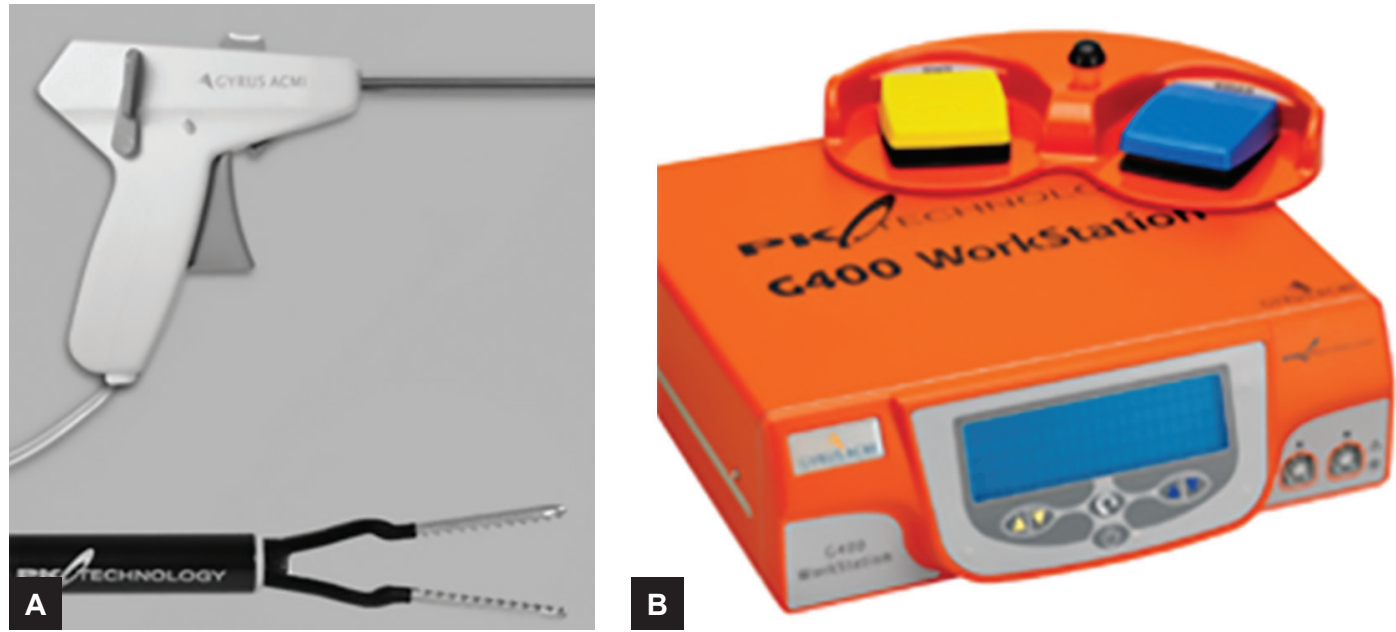

Figs 25A and B: (A) Gyrus PK integrated vessel sealing and cutting system (Olympus);

(B) Gyrus PK control unit (Olympus) 


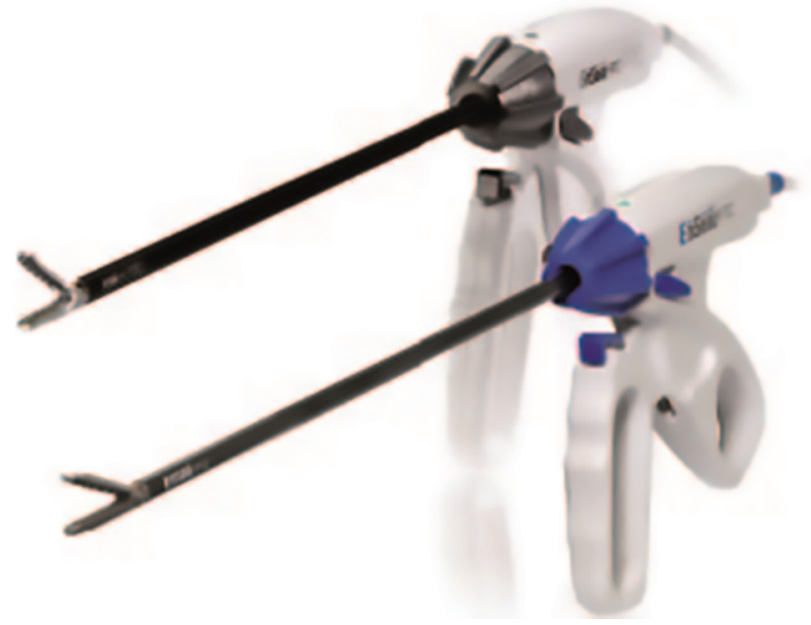

Fig. 26: ENSEAL sealing instrument (Ethicon Endo-Surgery)

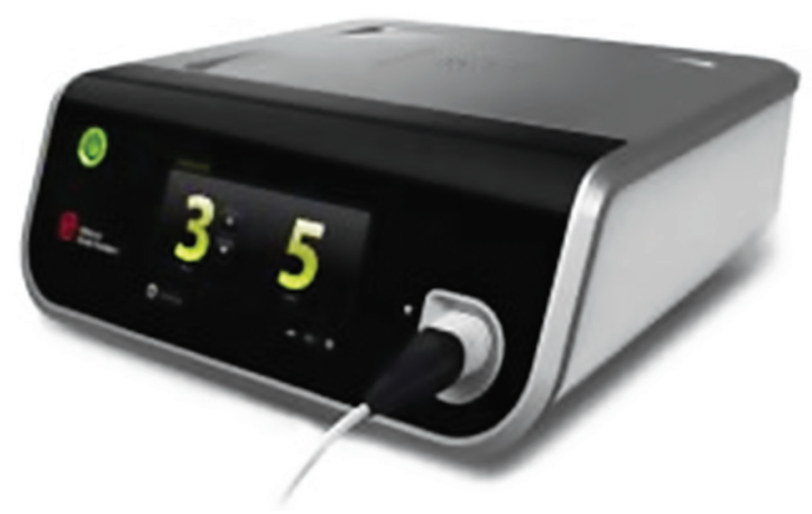

Fig. 28: Harmonic ace control unit (Ethicon)

arising from the fiber bundle, the effect can be achieved only up to $2 \mathrm{~cm}$ from the tip of the fibers. Wallwiener et $\mathrm{al}^{24}$ introduced laser treatment in reproductive surgery.

Harmonic scalpel-ultrasonic energy: The harmonic scalpel is an ultrasonically activated laparoscopic instrument that uses mechanical energy to cut and coagulate tissues. Today, the harmonic scalpel can be used as 5 to $10 \mathrm{~mm}$ cutting blades and scissors. Activation of the titanium blade takes place by a piezoelectric crystal with a frequency of 55,500/second in the handset. The cutting and coagulation effects are comparable to that of the $\mathrm{CO}_{2}$ laser. $^{25}$ The lateral thermal damage is less than by HF coagulation. Burning and carbonization of tissues are not observed.

The advantages of ultrasound energy in surgical endoscopic instruments produced by Ethicon EndoSurgery and Olympus are well known today and highly appreciated. As an example, let us focus on the harmonic ace of Ethicon (Fig. 27) which with its specific control unit (Fig. 28) allows a shorter and a longer effect of sealing and cutting. The mechanical energy works with low temperatures, small lateral damage, and minimal desiccation of the tissue.

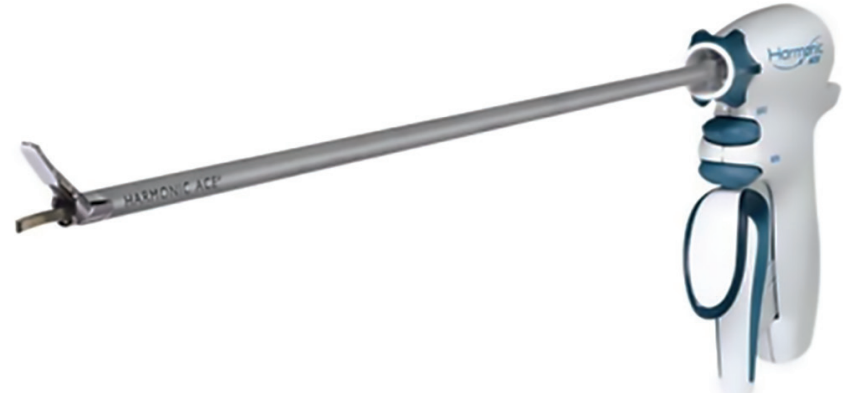

Fig. 27: Harmonic ace forceps (Ethicon)

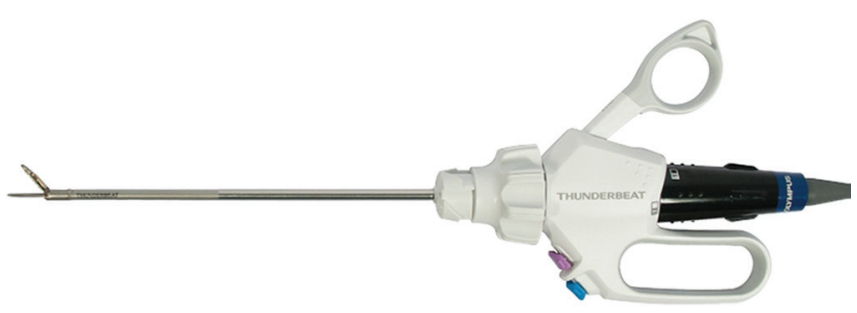

Fig. 29: Thunderbeat (Olympus)

Olympus unites in its excellent coagulation and cutting device "Thunderbeat" thermofusion, and ultrasound technology increasing our surgical speed of actions and safety (Fig. 29).

The different harmonic instruments on the market today, such as harmonic shears, forceps, and cutting rings, are applied for adhesiolysis as well as any type of adenexectomy, ovarectomy, and hysterectomy. It remains up to the surgeon whether he uses them in combination with other sealing instruments or bipolar coagulation.

\section{Summary of Specific Instruments to be used in TLH}

All the above-mentioned instruments are excellent tools to be used for TLH. There are two ways of applying traction and contra-traction for the operative field either by using an intrauterine manipulator in uteri up to a certain size or using traction with a myoma screw, introduced from the lateral ports, a principle widely applied in "Radical hysterectomies" in cases of malignancies. The absolutely necessary instruments for TLH, with or without adnexectomies, are detailed in Figure 30.

\section{Summary of Specific Instruments to be used in SLH}

Subtotal hysterectomy, also known as CISH (Classic Intrafascial Supracervical Hysterectomy) or LSH (Laparoscopic-Assisted Supracervical Hysterectomy), is facilitated by the use of an electric loop produced by LiNA Medical ApS, Glostrup, Denmark (Fig. 31) as 
TLH Tools

- 1 Trocar 11-5 mm

- 1-2 Versaport* $12-5 \mathrm{~mm}$ Trocars (left and right side)

- 1 Bipolar Instrument $5 \mathrm{~mm}$ or EnSeal or LigaSure

- 1 Scissor $5 \mathrm{~mm}$

- 1 Grasper $10 \mathrm{~mm}$ (huge uterus)

- Uterus manipulator (Hohl)

- 1 monopolar hook $5 \mathrm{~mm}$

- 1 suture

- 1 needle holder
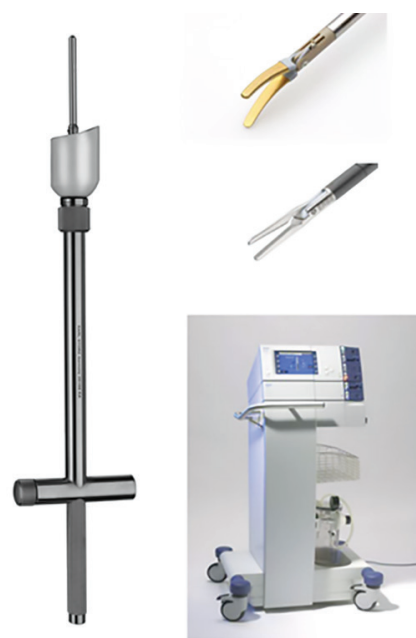

Fig. 30: Instrument set for TLH

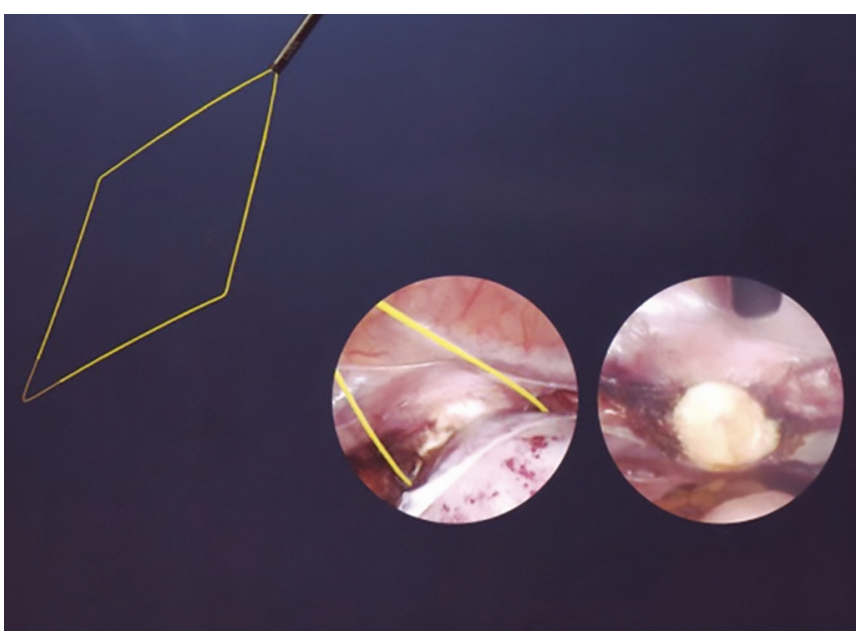

Fig. 31: LiNA Loop at SLH

SLH Tools

- 1 Trocar 11-5 mm for 0/30 Laparoscope

- 1 Versaport 12-5 mm Trocars (left) 1 Trocar $5 \mathrm{~mm}$ (right side)

- 1 Bipolar Instrument $5 \mathrm{~mm}$ or EnSeal or LigaSure

- 1 Scissor $5 \mathrm{~mm}$

- 1 Grasper 10 mm (only huge ute)

- 1 Monopolar hook or 1 LiNA Loop or STORZ loop

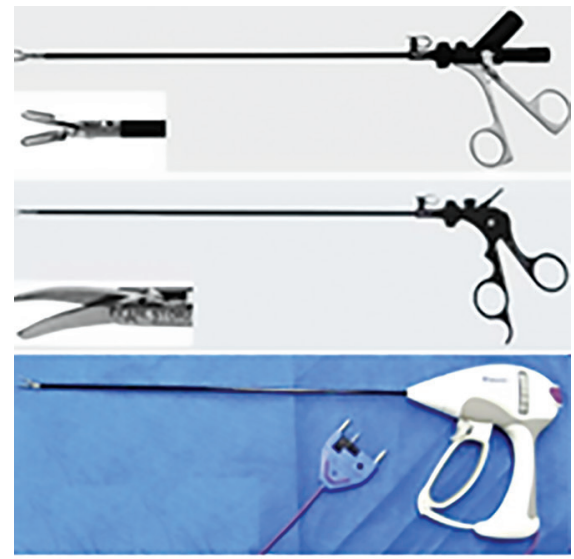
of them is that the laparoscope can be passed through the Veress needle or the sleeve. Additional trocar insertion after gas insufflation is therefore superfluous. However, compared with the standard 5 and $10 \mathrm{~mm}$ optics, even the most satisfactory of the mini-systems shows deficient lighting efficiency. The instrument trocars are also available in correspondingly small diameters.

The merits of minimal operative trauma and the avoidance of umbilical trocar insertion done by inserting the laparoscope through the Veress cannula in mini-laparoscopies used to have disadvantages, such as the mechanical fragility of the mini-laparoscopes and difficult operative sites with a restricted view. Today, new optics and stabile instruments have virtually eliminated these disadvantages. Therefore, a set of mini-laparoscopic instruments must always be available for use in certain surgical interventions. The small diameter of the mini-instruments contributes toward reducing trauma and pain in children and in smaller surgical procedures. 1 Dissecting Hook (harmonic)

- 1 Rotocut G1 morecellator system, in bag morcellation

- 1 suture

- 1 needle holder
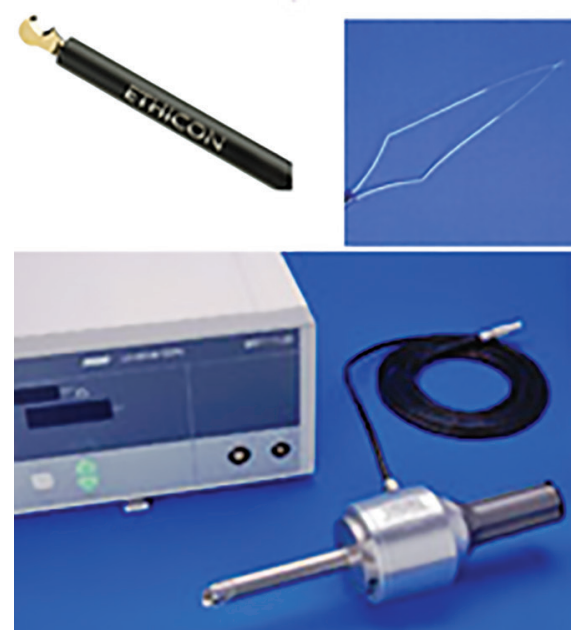

Fig. 32: Instrument set for SLH

For TLH and SLH, small uteri microendoscopic instruments can be used. However, there should be no limitation to combine the procedure by using conventional laparoscopic instruments, as well.

\section{Single-port or Single-entry Laparoscopy (SEL)}

Laparoscopy in the 1940s started with the angled laparoscope (optic and one working channel) of Raoul Palmer in 


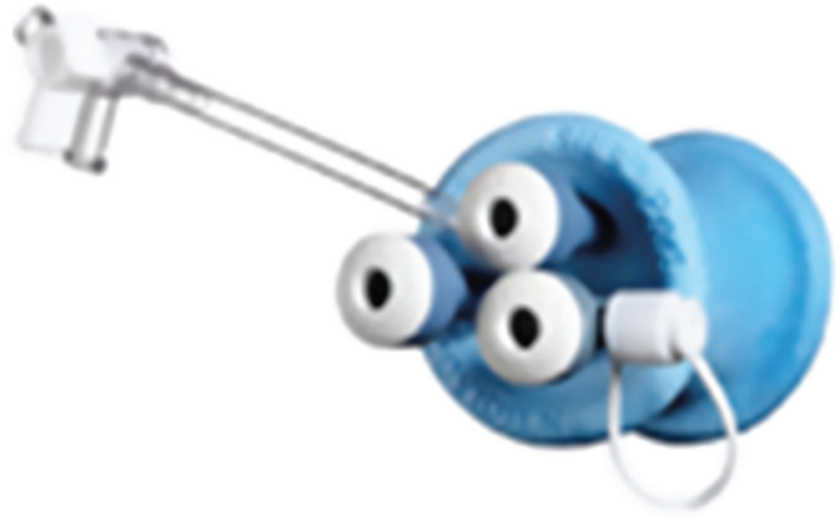

Fig. 33: LESS—Laparo-endoscopic single-site surgery (Olympus)

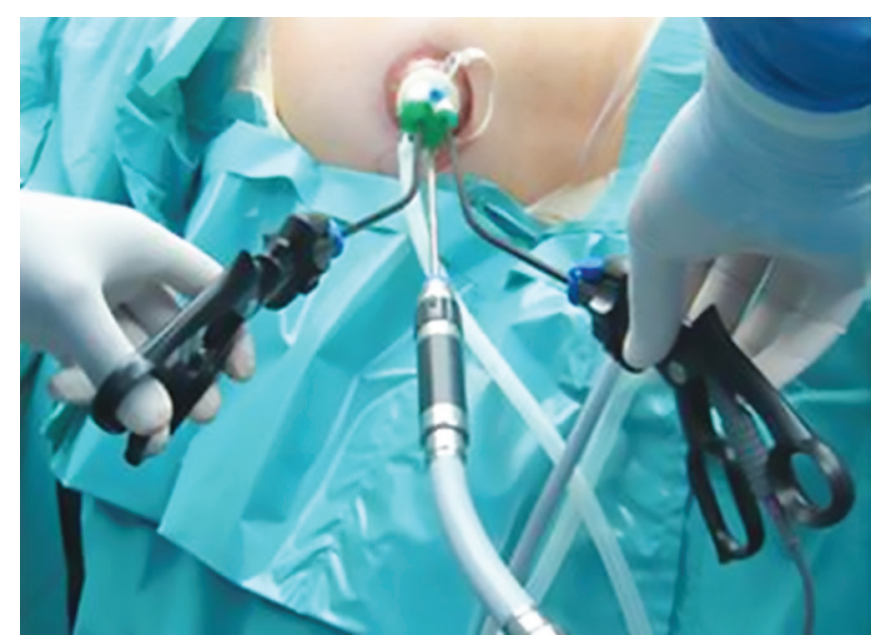

Fig. 35: Seven variations of LESS curved instruments (Olympus)

France as SEL. Laparoscopy at that time was mainly used for diagnostic purposes and for sterilizations. KurtSemm (from Germany) further developed the procedure into operative laparoscopy by using multiple entries and instruments.

Today, with the improved technology, SEL takes the idea of early laparoscopy to new horizons. Of the multitude of SEL ports available, let us mention two disposable and one reusable:

- The SILS port (Covidien) (Fig. 33) is a disposable port. Here, a silicone port is introduced into the abdominal cavity using a classical curved grasper with a beak of 5 to $6 \mathrm{~cm}$. The surgeon has the choice of two ports of $5 \mathrm{~mm}$ and one allowing for a large barrel instrument of 10 to $12 \mathrm{~mm}$ or one with four $5 \mathrm{~mm}$ ports. The SILS, with the possibility to introduce larger instruments, is suitable for hysterectomies.

- Another disposable port is the LESS QuadPort + (Fig. 34) of Olympus which contains duckbill valves and requires no gel for insertion. Instruments of 5, 10, 12 , and $15 \mathrm{~mm}$ can be introduced easily for ergonomic surgery. The $5 \mathrm{~mm}$ LESS EndoEYE video laparoscopes provide excellent visualization and help to avoid instrument clashing. Specialized curved HiQ + LESS

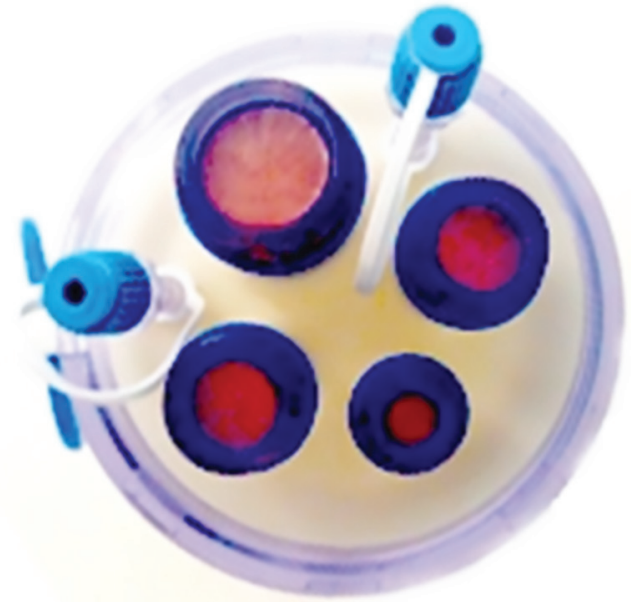

Fig. 34: LESS system with EndoEYE and curved instruments (Olympus)

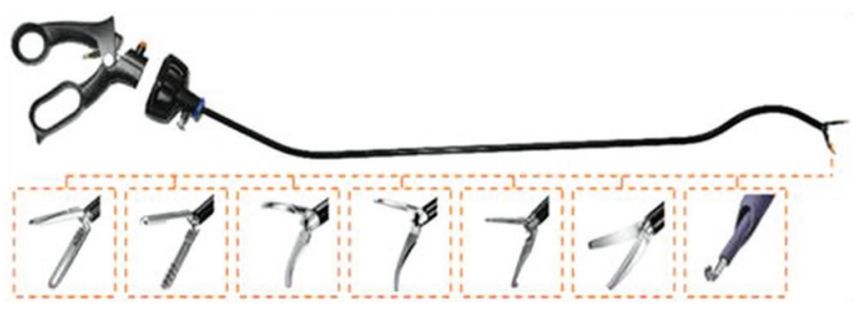

Fig. 36: XCONE (Karl Storz)

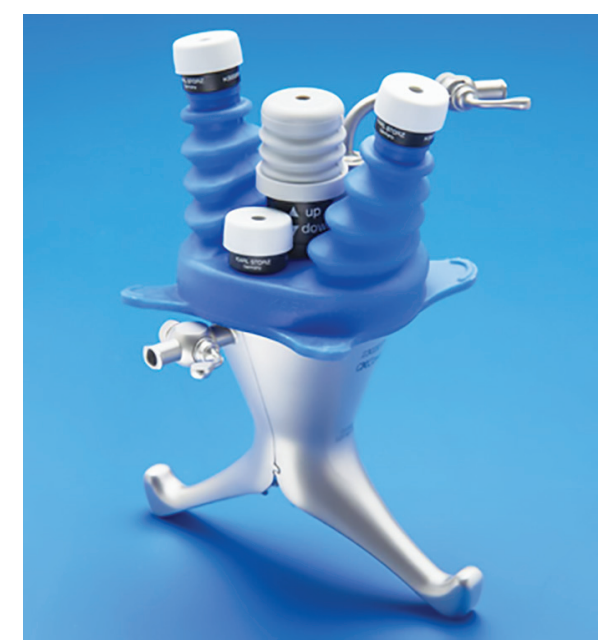

Fig. 37: ENDOCONE ${ }^{\circledR}$ (Karl Storz)

instruments allow internal triangulation and mimic traditional laparoscopy (Figs 33 to 36). As a reusable port, we use the XCONE (Figs 36 and 37) of Karl Storz. This system is operational in the abdomen with 3 to 5 entry channels, one allowing large barrel instruments. Usually the 3 or $5 \mathrm{~mm}$ optic is placed into the middle entry and at least one curved instrument on the left or right side. The ENDOCONE ${ }^{\circledR}$ (Fig. 37) is a special access system developed by the general surgeon Cuschieri in which seven instruments can be introduced simultaneously. 
Developments are ongoing as can be seen by the ETHOS Surgical Platform ${ }^{\text {TM }}$ (Ethos Surgical, Beaverton, USA), on which the surgeon is postured over the midline of the patient with optimal port triangulation options. New instruments and apparatuses are continuously being appraised. They assist the surgeon but do not replace his knowledge and have to be always critically evaluated and studied before they are applied.

For TLH and SLH at single-port laparoscopy, an intrauterine manipulator is essential to be used in combination with the following necessary instruments: Graspers, coagulation devices, scissors, electro loop, and a morcellator ${ }^{26}$ in specific cases, where contained morcellation is more and more applied.

In summary, conventional laparoscopic hysterectomies with single and multiple port entries are easy to be performed with modern gyne-endoscopic instrument and apparatuses. We are not dealing with robotic surgery in this essay, however, we are well aware of its advantages and challenges.

\section{REFERENCES}

1. Semm K, editor. Operationslehre für endoskopische Abdominal-Chirurgie. Stuttgart (NY): Schattauer; 1984.

2. Reich H, DeCaprio J, McGlynn F. Laparoscopic hysterectomy. J Gynecol Surg 1989;5(2):213-216.

3. Semm K. CISH (pelviscopic intrafascial hysterectomy-without colpotomy), TUMA (total uterine mucosa ablation) and IVH (intrafascial vaginal hysterectomy). Gynakologe 1993 Dec;26(6):378-384.

4. Dargent D, Audra P, Miellet CC. Better use of POR 8. Presse Med 1986 Jun;15(23):1106.

5. Weibel MA, Majno G. Peritoneal adhesions and their relation to abdominal surgery. A postmortem study. Am J Surg 1973 Sep;126(3):345-353.

6. Menzies D, Ellis H. Intestinal obstruction from adhesionshow big is the problem? Ann R Coll Surg Engl 1990 Jan;72(1): 60-63.

7. Hawthorn RJS, Lower A, Clark D, Knight AD, Crowe AM. Adhesion-related readmissions following gynaecological laparoscopy in Scotland, an epidemiological study of 24,046 patients. Rev Gynaecol Pract 2003;3:1.

8. Beck DE, Opelka FG, Bailey HR, Rauh SM, Pashos CL. Incidence of small-bowel obstruction and adhesiolysis after open colorectal and general surgery. Dis Colon Rectum 1999 Feb;42(2):241-248.

9. Hershlag A, Diamond MP, DeCherney AH. Adhesiolysis. Clin Obstet Gynecol 1991 Jun;34(2):395-402.

10. Holmdahl L, Risberg B. Adhesions: prevention and complications in general surgery. Eur J Surg 1997 Mar;163(3): 169-174.
11. Beck DE, Ferguson MA, Opelka FG, Fleshman JW, Gervaz P, Wexner SD. Effect of previous surgery on abdominal opening time. Dis Colon Rectum 2000 Dec;43(12):1749-1753.

12. Lower AM, Hawthorn RJ, Ellis H, O'Brien F, Buchan S, Crowe AM. The impact of adhesions on hospital readmissions over ten years after 8849 open gynaecological operations: an assessment from the Surgical and Clinical Adhesions Research Study. BJOG 2000 Jul;107(7):855-862.

13. Dubuisson JB, Fauconnier A, Chapron C, Kreiker G, Norgaard C. Second look after laparoscopic myomectomy. Hum Reprod 1998 Aug;13(8):2102-2106.

14. Sekiba K. Use of Interceed (TC7) absorbable adhesion barrier to reduce postoperative adhesion reformation in infertility and endometriosis surgery. The Obstetrics and Gynecology Adhesion Prevention Committee. Obstet Gynecol 1992 Apr;79(4):518-522.

15. Vrijland WW, Tseng LN, Eijkman HJ, Hop WC, Jakimowicz JJ, Leguit P, Stassen LP, Swank DJ, Haverlag R, Bonjer HJ, et al. Fewer intraperitoneal adhesions with use of hyaluronic acidcarboxymethylcellulose membrane: a randomized clinical trial. Ann Surg 2002 Feb;235(2):193-199.

16. Mettler L, Audebert A, Lehmann-Willenbrock E, Schive-Peterhansl K, Jacobs VR. A randomized, prospective, controlled, multicenter clinical trial of a sprayable, site-specific adhesion barrier system in patients undergoing myomectomy. Fertil Steril 2004 Aug;82(2):398-404.

17. Ferland R, Campbell PK. Pre-clinical evaluation of a nextgeneration spray adhesion barrier for multiple site adhesion protection. Surg Technol Int 2009 Apr;18:137-143.

18. Metwally M, Watson A, Lilford R, Vandekerckhove P. Fluid and pharmacological agents for adhesion prevention after gynaecological surgery. Cochrane Database Syst Rev 2006 Apr;2:CD001298.

19. Mettler L, Hucke J, Bojahr B, Tinneberg HR, Leyland N, Avelar R. A safety and efficacy study of a resorbable hydrogel for reduction of post-operative adhesions following myomectomy. Hum Reprod 2008 May;23(5):1093-1100.

20. Veress J. Neues Instrument zur Ausführung von Brust oder Bauchpunktionen und Pneumothoraxbehandlung. Dtsch Med Wochenshr 1938;41:1480-1482.

21. Semm K. Die moderne Endoskopie in der Frauenheilkunde. Frauenarzt 1972;13:300-307.

22. Hopkins HH. On the diffraction theory of optical images. Proc Roy Soc A 1953 May;217(1130):408-415.

23. Brill AI. Energy systems for operative laparoscopy. J Am Assoc Gynecol Laparosc 1998 Nov;5(4):333-345; quiz 347-349.

24. Wallwiener D, Maleika A, Rimbach S, Homann G, Rabe T, Gauwerky J, Basiert G. The value of laparoscopic and laserassisted techniques in reconstruction of distal fallopian tube pathology. Zentralbl Gynakol 1996;118(2):66-72.

25. Schemmel M, Haefner HK, Selvaggi SM, Warren JS, Termin CS, Hurd WW. Comparison of the ultrasonic scalpel to CO2 laser and electrosurgery in terms of tissue injury and adhesion formation in a rabbit model. Fertil Steril 1997 Feb;67(2):382-386.

26. Alkatout I, Mettler L, editors. Hysterectomy: a comprehensive surgical approach. 1st ed. Switzerland: Springer; 2017. 